\title{
Semiconductor Disk Lasers: Recent Advances in Generation of Yellow-Orange and Mid-IR Radiation
}

\author{
Mircea Guina, Antti Härkönen, Ville-Markus Korpijärvi, \\ Tomi Leinonen, and Soile Suomalainen \\ Optoelectronics Research Centre, Tampere University of Technology, P.O. Box 692, 33101 Tampere, Finland \\ Correspondence should be addressed to Mircea Guina, mircea.guina@tut.fi
}

Received 15 September 2011; Accepted 23 November 2011

Academic Editor: Rainer Michalzik

Copyright (C) 2012 Mircea Guina et al. This is an open access article distributed under the Creative Commons Attribution License, which permits unrestricted use, distribution, and reproduction in any medium, provided the original work is properly cited.

\begin{abstract}
We review the recent advances in the development of semiconductor disk lasers (SDLs) producing yellow-orange and mid-IR radiation. In particular, we focus on presenting the fabrication challenges and characteristics of high-power GaInNAs- and GaSbbased gain mirrors. These two material systems have recently sparked a new wave of interest in developing SDLs for high-impact applications in medicine, spectroscopy, or astronomy. The dilute nitride (GaInNAs) gain mirrors enable emission of more than $11 \mathrm{~W}$ of output power at a wavelength range of $1180-1200 \mathrm{~nm}$ and subsequent intracavity frequency doubling to generate yelloworange radiation with power exceeding $7 \mathrm{~W}$. The GaSb gain mirrors have been used to leverage the advantages offered by SDLs to the 2-3 $\mu \mathrm{m}$ wavelength range. Most recently, GaSb-based SDLs incorporating semiconductor saturable absorber mirrors were used to generate optical pulses as short as $384 \mathrm{fs}$ at $2 \mu \mathrm{m}$, the shortest pulses obtained from a semiconductor laser at this wavelength range.
\end{abstract}

\section{Introduction}

Conceptually, the idea of an optically pumped semiconductor disk laser (OP-SDLs) was suggested already in 1966 by Basov et al. in a paper describing lasers with radiating mirrors [1]. However, it was not until the 1990s that the concept was acknowledged and the first working devices were reported [2-6]. In its essence, the concept of an OP-SDL is based on using an optically pumped semiconductor gain structure (i.e., gain mirror) with vertical emission. We note here that in addition to OP-SDL, also acronyms like OP-VECSEL (optically pumped vertical external-cavity surface-emitting laser) and OPSL (optically pumped semiconductor laser) are commonly used in literature to describe the same type of laser. The laser resonator is typically formed between the gain mirror and one or more external-cavity mirrors. In many ways, this laser architecture is similar to that of traditional solid state disk lasers. An essential difference is that in traditional solid state lasers the emission wavelength is dependent on certain fixed atomic transitions in a host material, whereas in an SDL the wavelength can be specifically tailored in a wide range by engineering the composition of the semiconductor material. This added wavelength versatility is one of the key factors that have made SDLs successful also commercially.

Technically speaking, the OP-SDL can be considered as a brightness and wavelength converter; it converts low brightness light from multimode diode pump lasers into a high brightness single mode beam at a wavelength that is longer than the pump wavelength. Compared to edge emitting diode lasers and vertical-cavity surface-emitting lasers (VCSELs), the external cavity and optical pumping make the SDLs more complicated but they also bring several benefits. First of all they enable upscaling of the mode area on the gain while still maintaining single transversal mode operation; consequently the output power can be increased to multiwatt levels without risk of catastrophic optical damage due to excessively high optical intensities. In addition, the external cavity allows for cascading multiple gain mirrors thus increasing even more the power scaling capability. The SDL cavity has a high Q-factor and therefore it stores optical energy allowing efficient nonlinear intracavity frequency conversion to visible wavelengths. Another benefit of the external cavity is that it enables incorporation of nonlinear components to initiate ultrashort pulse operation. We should 
also note that lately, the cost of broad stripe edge emitting pump diodes at 790-980 $\mathrm{nm}$ wavelengths has decreased significantly, while at the same time the available power from both single emitters and diode bars has increased markedly. More recently, also high-power pump diodes at other important wavelengths, including 635-690 nm, 1480-1550 nm, and $2000 \mathrm{~nm}$, have been commercialized more actively. These advances in the availability, cost, and performance of pump diodes have made the optical pumping concept even more attractive.

1.1. Cavity Designs. Structurally the SDL gain mirror resembles a half-VCSEL design that comprises a high reflectivity mirror and a semiconductor gain region. The gain region usually includes several quantum-well (QW) or quantum$\operatorname{dot}(\mathrm{QD})$ layers separated by spacer/barrier layers. A typical mirror structure consists of a stack of quarter-wavelength semiconductor layers, forming a distributed Bragg reflector (DBR), although metallic, dielectric, or hybrid [7] mirror structures can be used in some cases as well. While in VCSELs the single transverse mode operation is achieved by confining the laser mode to a very small gain area, in SDLs the same functionality is achieved by controlling the fundamental mode size via cavity design to have it match with the pumped area on the gain. Figure 1 shows various cavity configurations of SDLs.

The simplest conventional SDL cavity has an I-shape that is formed between the gain mirror and a single external output coupler (OC) mirror. However, in practice it is often easier to use a V-shaped cavity formed between the gain mirror, one curved folding mirror, and a planar output coupler. The advantage of the V-cavity is that planar output couplers with various coupling ratios are often cheaper and more widely available on stock than equivalent curved couplers. Another practical advantage of the $\mathrm{V}$-shaped cavity is related to the alignment of the laser; if the final alignment is done by monitoring the output of a photodiode placed behind the output coupler, the folding mirror in a V-shaped cavity collects the light efficiently to the photodiode enhancing the available signal while in I-shaped cavity the spontaneous emission from the gain is rapidly dispersed to all direction. More complex cavity configurations are often used for frequency conversion and mode-locking. For efficient frequency conversion the nonlinear crystal is often placed at a location near or at the mode waist. This is usually easier to do in a V-shaped or Z-shaped cavity than in an I-shaped cavity. More complicated Z-shaped cavities are typically used in mode-locking SDLs to accommodate also a semiconductor saturable absorber mirrors (SESAMs); the challenge here is to produce sufficiently small mode diameter on the absorber mirror, while at the same time maintaining reasonably large mode diameter on the gain [8]. One should notice though that the overall cavity length increases for more complex designs and the mode-locked pulse repetition rate is reduced. This in turn would reduce the efficiency; if the interval of consequent pulses is longer than the carrier-lifetime, which is typically in the ns-range or slightly below, there will be loss of pump energy in time. In other words, the gain element can store energy only for a limited time, and if it is not exploited

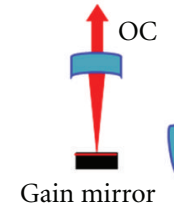

(a)

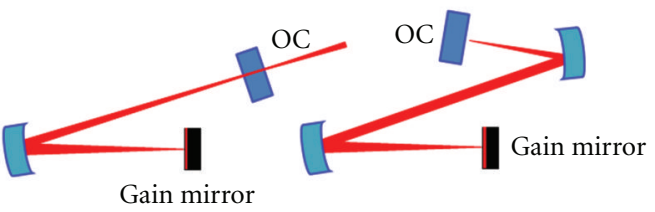

(b)

(c)
FIgure 1: Typical SDL cavities. (a) I-shaped cavity; (b) V-shaped cavity; (c) Z-shaped cavity. OC: output coupler.

in that time window by an incoming pulse, a portion of that energy will be lost to spontaneous emission between the consequent pulses. This feature sets a practical upper limit for the cavity length in mode-locked laser with continuous wave pumping.

To scale up the power of an SDL, it is possible to deploy multiple gain elements in single cavity [9-11]. SDLs can also employ ring cavities [12], but probably due to the added complexity such lasers have not gained much popularity. In addition to different external cavity configurations, one can also produce an SDL with a semimonolithic cavity that may include a plane-plane design stabilized by a thermal lens [13, 14]. Such laser may be more limited in power and brightness but does possess an extremely rugged design. Furthermore, the semimonolithic cavity can be processed to have curved surfaces with mirror structures, thus avoiding the need for cavity stabilization by a thermal lens [15].

1.2. Thermal Management of SDLs. Efficient thermal management is a very important aspect required for high-power operation of SDLs. Although heroic in many ways, the early SDL experiments required the use of very low temperatures for high-power operation making the devices unpractical for use outside the laboratory. To large extent this was caused by a lack of adequate heat dissipation techniques. Excess heating reduces the emission efficiency via increased nonraditive recombination and carrier leakage and red-shifts the emission wavelength, which in a resonant periodic gain structure [16] leads also to a mismatch between the emission wavelength and the resonant wavelength further reducing the gain. Effectively, such heat-induced processes create a positive feedback loop with very negative impact on the laser performance. Consequently, the output power of the laser exhibits a roll-over characteristic when the pump power is increased beyond a critical point. For high-power operation, one should implement adequate ways of thermal management. Heating of the gain mirror originates from pump energy, which is converted to useful photons only partially while another part of the pump energy is transferred to phonons due to nonradiative recombination and the quantum defect (i.e., the photon energy difference between the pump photon and the laser photon). As a general strategy, one should try to minimize the heat generation and at the same time maximize the heat transfer from the gain.

Typically the pump photon has markedly higher photon energy than the emitted laser photon; for example, for a $1060 \mathrm{~nm}$ laser pumped with $808 \mathrm{~nm}$ radiation, the quantum 


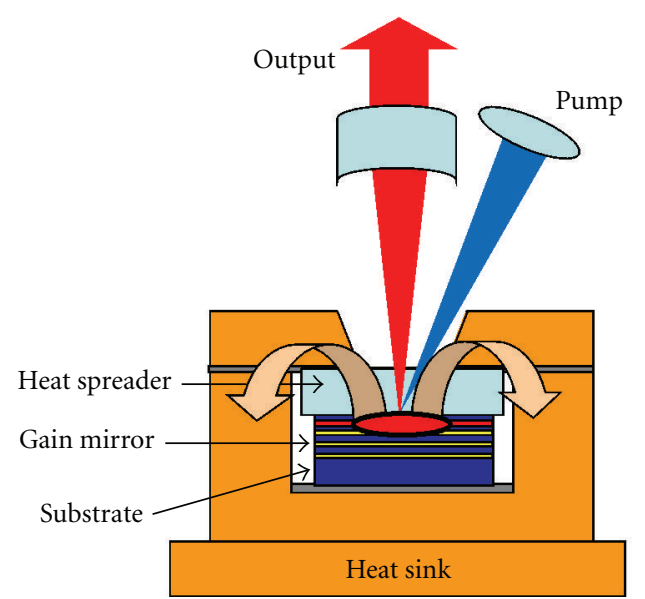

(a)

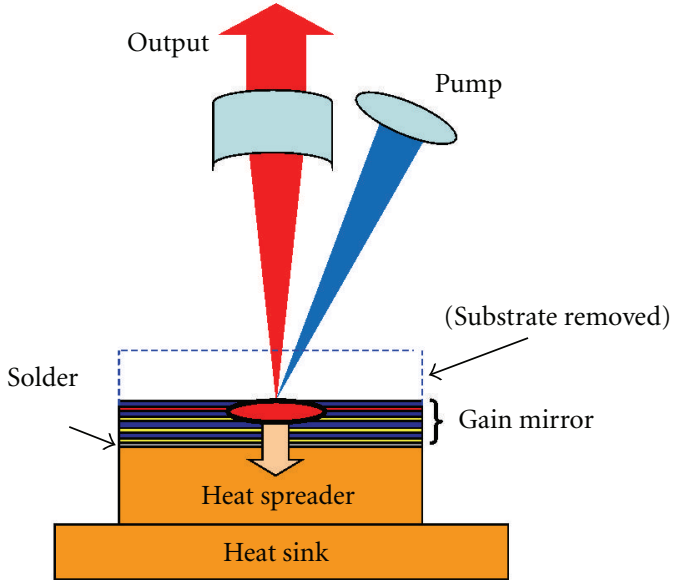

(b)

FIGURE 2: Description of two heat extraction strategies. (a) Laser equipped with intracavity heat spreader. (b) Flip-chip mounted thin-device from which the semiconductor substrate is removed.

defect is about $24 \%$ of the pump photon energy. In other words, the optical-to-optical conversion efficiency of such laser cannot exceed $76 \%$ even under theoretically perfect conditions. Usually, the laser is designed to absorb the pump radiation in the spacer/barrier layers separating the QWs because in this way the interaction length of light in matter is long enough to absorb sufficient amount of pump energy in a single pass. On the other hand, there must be a notable bandgap contrast between the spacer layers and the QWs in order to ensure a good carrier confinement and hence efficient operation at elevated temperatures. In most spacer pumped SDLs, the quantum defect is between $15 \%$ and $50 \%$ of the pump photon energy. An alternative for spacer pumping is direct "in-well" pumping [17-19] where the spacers are transparent to the pump radiation and the pump wavelength closely matches the QW emission wavelength. This approach minimizes the quantum defect but another technical difficulty arises from a short light-matter interaction length; the thickness of one QW is typically some nanometers and the total absorptive path length is rather small, as a gain mirror would typically include 5-15 QWs. To some extent, the pump absorption can be improved by adding more QWs to the structure but usually either a resonant pumping scheme or external pump recirculation optics is required for efficient pump absorption. We should note that an in-well pumped gain mirror provides by default a high reflection for the unabsorbed pump light, thus avoiding pump absorption in the DBR, and providing double-pass of pump radiation through the gain region. The selection of the pump laser for in-well pumping is more critical (and possibly more expensive) than in a spacer pumped laser where lowcost $808 \mathrm{~nm}$ diodes can be used for pumping $920 \mathrm{~nm}$ SDLs as well as $2000 \mathrm{~nm}$ SDLs. This is particularly true in the case of resonant in-well pumping. Nevertheless, in-well pumping offers an interesting option for reducing the quantum defect and the heating related to it. One should notice that quantum defect optimization makes sense only if the quantum efficiency of the laser is already high. If a significant majority of pump photons are anyway lost to nonradiative processes, the benefits of quantum defect optimization become marginal to the overall performance of the system. Therefore, highquality gain materials and proper structural designs are prerequisites for efficient operation of SDLs.

It is also very important to conduct the heat away from the gain region with minimal thermal resistance between the heat sink and the active region. Generally speaking, thermal resistance is dependent on the thermal conductance of the materials used and on the distance that heat needs to be transferred. In short, one should aim to minimize the distance between the heat sink and the gain and at the same time use materials that have high thermal conductance. Using a planar gain mirror geometry, the pumping is concentrated on an area that has typically a diameter of some tens or hundreds of micrometers, whereas the overall thickness of the semiconductor layer structure is only a few microns (e.g., 5-6 $\mu \mathrm{m}$ ). In other words, the heated area is very large compared to the thickness of the layers. Thermal simulations show that in such a structure the heat flow is essentially one dimensional and is directed normal to the sample surface [21]. We should point out that the epitaxial layers are grown on a semiconductor substrate that is typically some 200 $600 \mu \mathrm{m}$ thick and presents a major obstacle for the heat flow. Two assembling techniques of the gain mirror to the heat sink are typically employed to overcome this issue. The so-called "intracavity heat spreader" method, is conceptually simple and involves contacting a transparent heat spreader element onto the gain mirror [22] (see Figure 2 for general description). This method does not require substrate removal and the heat spreader is located right next to the gain region. The practical limitations arise from the fact that the heat spreader is located inside the laser cavity and that the number of transparent materials with high thermal conductance is limited; their cost may also be a limiting factor. By far the best material for this purpose is diamond due to its extremely high thermal conductance (up to $\sim 2000 \mathrm{~W} / \mathrm{m} \cdot \mathrm{K}$ ) and wide transmission window. Other suitable materials 
include, for example, silicon carbide ( $\mathrm{SiC}$ ) [23] and sapphire (crystalline $\mathrm{Al}_{2} \mathrm{O}_{3}$ ) [22]. A common technique for contacting the heat spreader and the semiconductor sample is based on capillary bonding [24] with deionized water or other suitable liquid. In this technique, two smooth and flat surfaces (here the gain mirror and heat spreader) are pulled together by surface tension of a liquid, and as the liquid evaporates, the two surfaces are brought to close optical contact and held together by surface forces. Simple mechanical clamping can be also used for optical contacting as long as the surfaces are sufficiently smooth, flat, and free from particles or other contaminants. However, capillary bonding is a good way to make sure that the surfaces meet these requirements and can be brought to close optical and thermal contact. The success of the bonding process can be simply monitored by observing the disappearance of the Newton's interference rings as the surfaces are brought together.

Another option for efficient heat dissipation was presented already in Kuznetsov's paper [25] and it involves growing the mirror and gain structures in reversed order (gain first, then the mirror) and bonding the component "upside-down" on a heat sink after which the substrate is removed by etching. Effectively this method transfers the epitaxial layers from a semiconductor substrate onto a substrate with higher thermal conductance. The process leaves only the Bragg reflector layers between the heated active region and the heat sink, which greatly reduces the thermal resistance in comparison to the situation where the semiconductor substrate would be located between the gain mirror and the heat sink. This process is often referred to as the "flipchip" process or the "thin-device" process. Sometimes these components are also called bottom emitters, a term that is commonly used in VCSEL processing. From processing point of view, the flip-chip process requires longer overall time but can be done in batches of many devices. The major challenge of the flip-chip approach relates to the fact that without the support of the original substrate the epitaxial layers are mechanically very fragile. The bonding process requires usually the use of temperatures exceeding $150^{\circ} \mathrm{C}$. Therefore, any differences in the coefficients of thermal expansion between the epitaxial layers and the heat sink may translate to mechanical stress as the sample cools down and the solder hardens. This is particularly critical issue with large samples bonded with hard solders such as AuSn that have high melting point. To alleviate the mechanical stress, one can resort to soft solders such as indium. However, it is a well-known fact that in high-power diode lasers indium solder tends to fail due to thermal diffusion and other effects. Such effects should be considered in connection with lifetime of high-power SDLs as the gain region is operated at relatively high temperatures. There are also many alternative bonding methods, such as InAu bonding $[7,26]$, that can be used instead. An important aspect related to soldering concerns the presence of voids within the solder; any voids in the solder will likely result in physical damage to the gain mirror under pumping. The voids can be monitored prior to substrate removal using a scanning acoustic microscope, for example. To further improve the heat dissipation, one can use a heat spreader, such as diamond, between the sample and the metallic heat sink; the thermal energy is thus rapidly spread from a point source to a larger area over which it is conducted to the actual heat sink. The cost of the heat spreader is also markedly reduced when there is no need for optical quality surface polishing. In addition to soldering the substrate removal is an important step in the flip-chip process. To some extent the substrate can be thinned by lapping, prior to bonding, but in any case tens or hundreds of microns of semiconductor substrate must be removed by etching. This is done usually by wet etching employing an etch stop layer. It is important for the success of the process that the selectiveness of the etching is sufficiently high and that the process can be carried out in reasonable time. For GaAs removal one can use, for example, InGaP or $\mathrm{Al}(\mathrm{Ga}) \mathrm{As}$ etch stop layers and $\mathrm{NH}_{4} \mathrm{OH}: \mathrm{H}_{2} \mathrm{O}_{2}$-based etchants. InP etchants are often based on $\mathrm{HCl}$ [27], which may limit or hinder the use of indium as a solder for sample bonding. For GaSb-based compounds, good etchantetch stop combinations are less developed; successful flipchip SDLs based on this material system were just recently reported [26].

When compared to the flip-chip design, the intracavity heat spreader approach has proved to be very quick and simple to do in laboratory conditions. The heat spreaders can be also recycled almost endlessly, which overcomes their high initial cost at least for research use. The intrinsic disadvantage of the intracavity heat spreader is that it introduces a loss element in the cavity that can also act as an etalon. The etalon effect modulates the optical spectrum affecting the modelocking mechanisms and making continuous wavelength tuning difficult. The etalon effect can be suppressed by using a wedged heat spreader with an antireflective coating [28]. The wedge angle usually increases the reflection losses despite the AR layer and hence decreases the output power. One should notice that inside the laser resonator, etalon effects may arise also from unexpected sources such as double-side polished semiconductor wafers onto which the gain mirror or the saturable absorber mirror may have been grown. Although the reflectivity of the gain mirror DBR is usually over $99.5 \%$, the small transmitted portion of light may penetrate to the substrate (if transparent) and can be reflected back from its second surface, in which case an etalon is established in the system and the spectrum of the laser is affected. Both heat management strategies have been successfully used to achieve over $10 \mathrm{~W}$ output from standard InGaAs/GaAs gain structures, though the highest output powers have been achieved with the flip-chip components $[29,30]$. However, if the thickness of the DBR stack increases (due to longer operation wavelength or poor index contrast of the materials), or if the DBR layers have very poor thermal conductance, it may be more advantageous to use the intracavity heat spreader technique. This is particularly true for InP- and GaSb-based SDLs. The thermal issues of SDLs have been discussed in detail in a number of papers reporting simulations and experimental results on the subject $[21,31-$ 34].

To summarize, efficient heat removal is highly important for high-power operation of SDLs. Use of high thermal conductance heat spreader materials, such as diamond, 


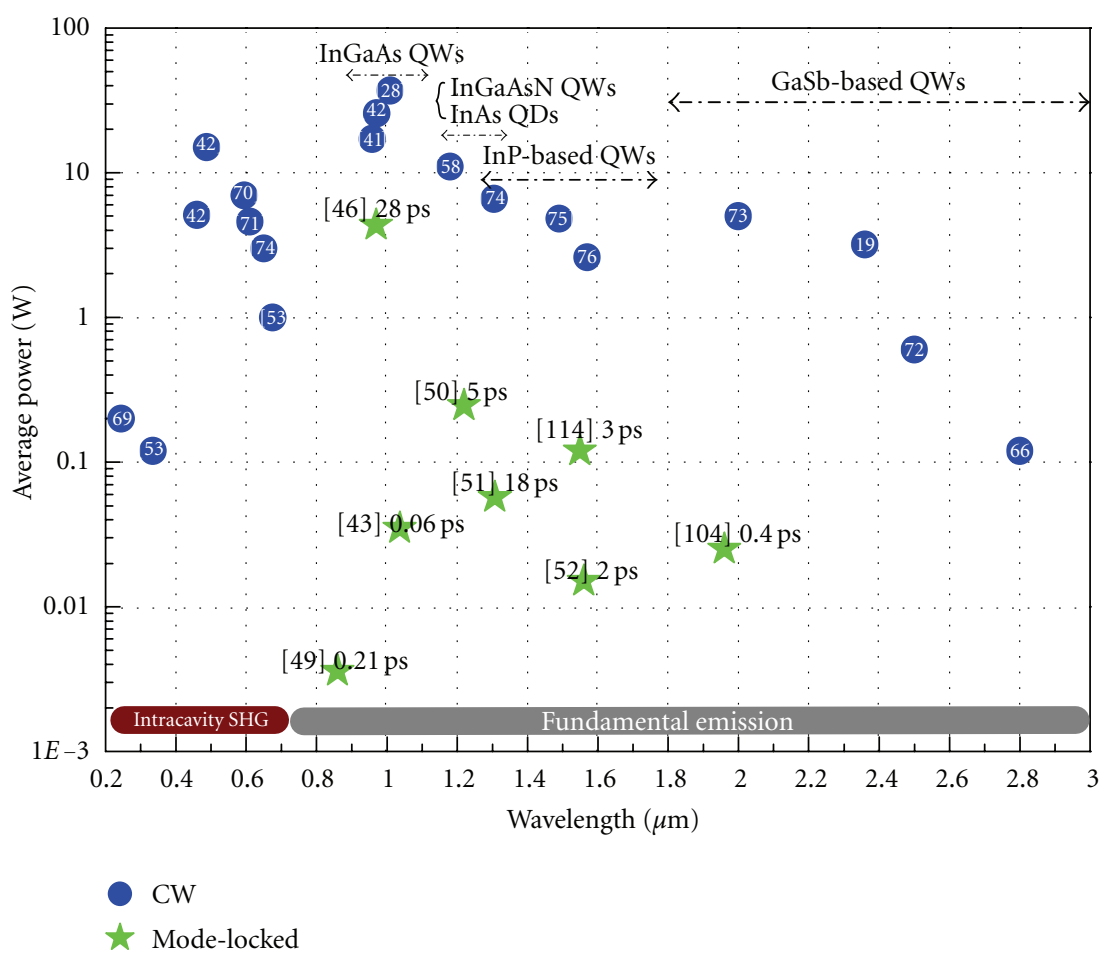

FIGURE 3: Selection of SDL results showing the maximum average power reached at different wavelengths. InGaAs(N)-based gain materials dominate the results up to $1.3 \mu \mathrm{m}$ above which InP-based and GaSb-based QWs are used. Only SDLs incorporating single gain chips are included. Pulse durations related to mode-locked results are given in picoseconds.

greatly improves the heat extraction from the point source. The distance from the gain region to the heat spreader can be minimized by optically contacting the heat spreader onto the sample or by flip-chip bonding the component on a heat spreader/heat sink. The application and the type of gain material determine which process is more suitable. Flip-chip processing suits well for mode-locking, continuous spectral tuning, and single-frequency operation since the laser spectrum is not affected by the intracavity heat spreader element. The intracavity heat spreader approach suits particularly well for long wavelength ( $\mathrm{GaSb}$ and InP) lasers and applications that are not spectrally sensitive.

1.3. Wavelength Coverage. During the last decade, the SDL research has been largely channelized along three major directions, namely, (i) power scaling, (ii) extending the wavelength coverage, and (iii) generation of ultrashort pulses. Along the way, many demonstrations concerned widely tunable [35-38] and narrow band lasers [39-41]. In terms of available output power, the $10 \mathrm{~W}$ level has been reached and exceeded using both single and multiple gain elements $[29,30,42,43]$. Excellent results have been obtained lately in ultrashort pulse generation $[44,45]$, as well as in generation of pulses with high average output power $[46,47]$ and high repetition rate [48]. The spectral coverage of mode-locked [49] SDLs has also extended [50-53] outside the common InGaAs wavelengths near $1 \mu \mathrm{m}$. Interestingly, the spectral coverage of continuous wave SDLs (fundamental and frequency converted emission) spans today from $244 \mathrm{~nm}$ to $5000 \mathrm{~nm}[18,20,22,23,37,54-76]$, although not without gaps. Figure 3 gives an overview of maximum output powers achieved as a function of wavelength for both continuouswave $(\mathrm{CW})$ and mode-locking operation regimes. It also provides a correspondence to main classes of material systems used to reach a certain wavelength region.

In terms of more recent efforts and development directions, the $580-630 \mathrm{~nm}$ wavelength range is particularly interesting as it cannot be reached via direct emission from semiconductors. Nevertheless, it can be covered conveniently by frequency doubled $1160-1260 \mathrm{~nm}$ infrared lasers. We should note that it is also difficult to find suitable solid state materials for these visible and IR ranges. Because of these reasons, there has been a lot of scientific and commercial interest in extending the SDL technology to this particular wavelength range. In the following we will review different options for reaching emission at $\sim 1150-1300 \mathrm{~nm}$ with semiconductors. First, it is important to understand the main features of the semiconductor structures we are considering for fabricating SDL mirrors. The gain mirror is essentially a stack of epitaxially grown semiconductor thin-films, fabricated on a GaAs, InP, GaSb, or other suitable semiconductor substrate by epitaxial growth. It is quite essential that one is able to grow high-quality gain material (QW, QD, or bulk) with desired bandgap energy, while keeping the material strain within reasonable limits. Secondly, the DBR should provide sufficient reflectance with a reasonable stack thickness and level of strain. Excessive material strain, arising from the difference between the lattice constants of the semiconductor layers, can lead to formation of crystalline defects and ultimately to relaxation of the layered structure. The 
TABLE 1: Different technologies used for fabricating SDLs with emission at 1150-1300 nm.

\begin{tabular}{|c|c|}
\hline Strategies for wavelength extension to $1150-1300 \mathrm{~nm}$ & Challenges \\
\hline GaAsSb/GaAs QW gain material [81] & $\begin{array}{l}\text { Low confinement of carriers in the QWs. } \\
\text { Poor temperature behavior }\end{array}$ \\
\hline InP-based gain with InP-based Bragg reflector [64] & $\begin{array}{l}\text { Compromised reflectivity, } \\
\text { Increased stack thickness, low thermal conductance of the DBR }\end{array}$ \\
\hline Hybrid mirrors with InP-based gain [7] & Compromised thermal conductance \\
\hline Wafer fusion of different gain and active regions [82] & $\begin{array}{l}\text { More expensive processing. } \\
\text { Two growths required for one component }\end{array}$ \\
\hline InAs/GaAs QDs $[83,84]$ & Reduced design flexibility and low modal gain \\
\hline Strain compensated high indium content InGaAs QWs [85] & Strain-related lifetime issues \\
\hline Dilute nitride GaInNAs/GaAs QWs [20, 62] & Formation of nitrogen-related defects \\
\hline
\end{tabular}

1150-1300 nm wavelength range has previously been very challenging for the growth of SDLs for two main reasons. First, for conventional InGaAs/GaAs QW material a relatively large content of indium must be used to reduce the bandgap energy to the desired value and the high indium content increases the lattice constant of the material causing buildup of strain in the layer structure. Alternatively, one could also resort to the use of InP-based QWs which work at $1.2 \mu \mathrm{m}-1.6 \mu \mathrm{m}$, but unlike with GaAs, the DBR materials lattice matched to InP have very low index contrast [7780]. Therefore, the thickness of the Bragg reflector must be increased significantly in order to achieve high reflectance. A number of techniques have been proposed to extend the emission wavelength of GaAs-based structures beyond the typical InGaAs spectral window near $1 \mu \mathrm{m}$ or to enable the use of InP-based gain regions in surface normal lasers; the main techniques have been listed in Table 1 with related challenges.

In the next sections, we will review the basic technological aspects regarding the development of dilute nitrides gain mirrors and the recent achievements concerning dilutenitride SDLs with yellow-orange emission. GaSb-based SDL emitting at around $2 \mu \mathrm{m}$ will be discussed in Section 3.

\section{High-Power Yellow-Orange SDLs Based on Dilute Nitride Gain Mirrors}

\subsection{Dilute Nitrides: Band-Gap Engineering and Gain Mirror} Technology. To produce yellow emission by second harmonic emission, the indium content of the conventional InGaAs/GaAs QWs needs to be relatively high ( $x>35 \%)$. The high indium content increases the compressive lattice strain close to the point where misfit dislocations start to appear. The high lattice strain, together with high operation temperatures, can strongly deteriorate the lifetime of a device based on such QWs [86]. By adding a small amount of $\mathrm{N}$ (typically less than $3 \%$ ) to InGaAs, one can reduce at the same time the lattice constant and the band-gap of the material. This opens up great opportunities for GaAs-based technology. For example, the compressive strain of InGaAs/GaAs material system can be compensated by $\mathrm{N}$ incorporation enabling emission at wavelengths up to $1.55 \mu \mathrm{m}$ [87]. These dilute nitride compounds can be in fact lattice matched to GaAs;
$\mathrm{Ga}_{1-x} \operatorname{In}_{x} \mathrm{~N}_{y} \mathrm{As}_{1-y}$ with $x \approx 2.8 y$ is lattice matched to GaAs whereas compositions with $x>2.8 y$ and $x<2.8 y$ lead to compressively and tensile strained compounds, respectively. Furthermore, GaNAs layers exhibit a tensile strain that can be used for balancing the compressive strain of GaInAs layers.

The dramatic effect of nitrogen on the band gap is generally explained as being caused by the small size and large electronegativity of $\mathrm{N}$ atoms (radius $\sim 0.068 \AA$, electronegativity $\sim 3.04$ in units of Pauling scale) as compared to As atoms (radius $\sim 0.121 \AA$, electronegativity $\sim 2.18$ ) of the host crystal. Such impurity atoms create localized energy levels close to the conduction band edge and, as a result, modify the conduction band structure of the alloy. The interaction between the localized states and the conduction band is usually modeled using a so-called band anticrossing model (BAC). BAC has been very successful in explaining anomalous properties of the dilute nitrides, especially the conduction band structure and the related electron effective mass [88-91]. The theoretical dependence of the GaInNAs band-gap as a function of $\mathrm{N}$ and In composition is shown in Figure 4 (the material parameters used for calculation are taken from [91]). The band gap decreases strongly by incorporating only a few percent of nitrogen and the $1200 \mathrm{~nm}$ wavelength range is readily achievable by using GaInNAs with relatively low $\mathrm{N}$ content. We should also note that nitrogen incorporation is associated with an increase of the nonradiative recombination centers [92]. Incorporation of higher amounts of nitrogen can cause clustering and phase separation [93] having a detrimental effect on the optical quality of the material. To some extent, this effect can be alleviated by rapid thermal annealing (RTA) which, however, leads to a considerable blue shift of the PL wavelength [94], an effect that should be taken into account in order to achieve the desired laser performance.

In general, the control and understanding of epitaxial processes used to fabricate dilute nitrides is rather challenging. For example, the range of suitable growth temperatures for fabricating high-quality dilute nitrides is narrower than that for growing GaInAs. The typical growth temperature for GaInNAs is in the range of $\sim 460^{\circ} \mathrm{C}$, while GaInAs QWs are grown typically at $\sim 520^{\circ} \mathrm{C}$. The highest performance InGaAsN-based heterostructures are routinely fabricated by molecular beam epitaxy [95]. The standard 




FIGURE 4: Band gap and lattice constant of dilute nitride GaInNAs.

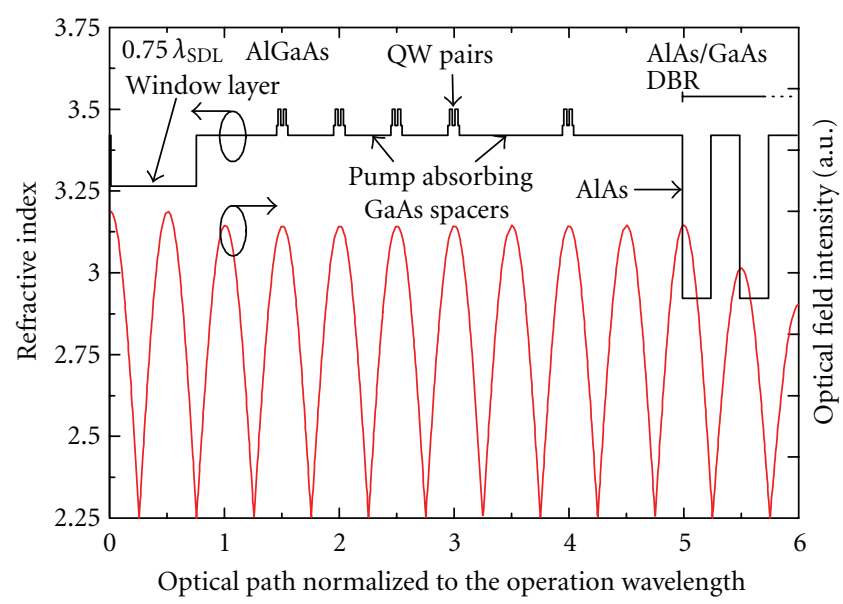

FIgURE 5: Typical structure of the quantum well region of a GaInNAs gain mirror [20].

technique used to incorporate $\mathrm{N}$ is dissociation of atomic nitrogen from molecular nitrogen using a radio-frequency (RF) plasma source attached to the MBE growth chamber [96]. Optimization of the plasma operation is one of the key issues that need to be addressed in order to fabricate high-quality dilute nitride heterostructures. The state of the nitrogen plasma depends on the RF power, the flow of $\mathrm{N}_{2}$, and pressure. The main constituents of the plasma are the molecular nitrogen, atomic nitrogen, and nitrogen ions, each of them having a specific spectral signature that can be used for optimizing the plasma operation [97]. Although the energy of the ions is small, they can cause significant degradation of the optical quality as they impinge on the semiconductor structure during the formation of the QWs [94]. Another important growth parameter affecting the quality of dilute nitrides is the As pressure [98].

Figure 5 displays the structure of a typical dilute nitride gain mirror comprising $10 \mathrm{Ga}_{0.33} \mathrm{In}_{0.67} \mathrm{~N}_{0.006} \mathrm{As}_{0.994}$ QWs placed in five pairs. The $\mathrm{GaN}_{0.006} \mathrm{As}_{0.994}$ layers surrounding the QWs shift their ground state to lower energy and compensate for the compressive strain. For achieving lasing at

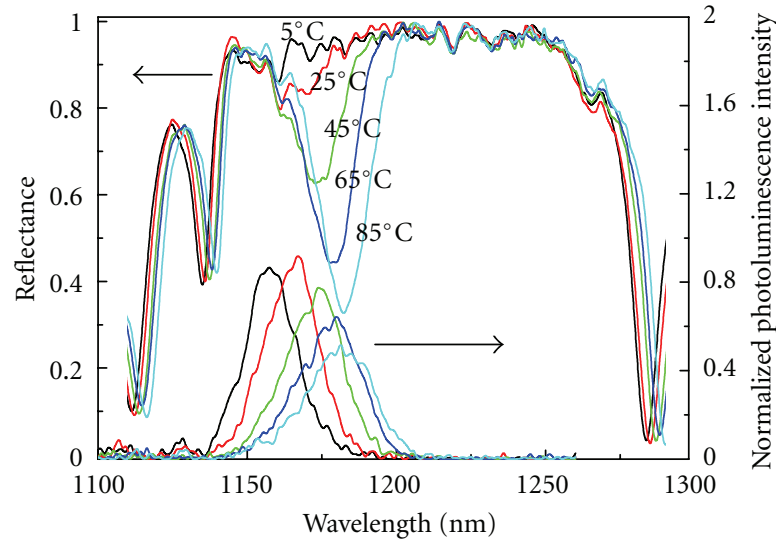

FIGURE 6: Reflectance and photoluminescence spectra of the $1180 \mathrm{~nm}$ GaInNAs gain mirror measured at different temperatures.

around $1180 \mathrm{~nm}$, the room temperature emission wavelength of the QWs was designed to be $\sim 1145 \mathrm{~nm}$. The first four QW pairs were equally spaced at one half wavelength distance apart from each other. The last QW pair was located a full wavelength distance apart from the fourth pair in order to compensate for the pump intensity drop along the gain structure. A $0.75-\lambda \mathrm{Al}_{0.25} \mathrm{Ga}_{0.75}$ As window layer was grown on top of the active region. The active region was grown on top of a 25.5-pair AlAs/GaAs DBR. The growth rate was $0.95 \mu \mathrm{m} /$ hour and the As/III beam equivalent ratio was 25 . After the growth, the sample was kept in the growth chamber under As pressure for a $7 \mathrm{~min}$ in situ anneal at $680^{\circ} \mathrm{C}$ to improve the luminescence properties.

The reflectance and photoluminescence (PL) spectra measured for different temperatures of the gain mirror are displayed in Figure 6. The PL graph reveals a temperature dependent red-shift of about $0.3 \mathrm{~nm} / \mathrm{K}$. The reason for the decrease in the PL intensity is the increase in the nonradiative recombination rate with increasing temperature resulting in a quantum efficiency drop. The DBR exhibits a temperature red-shift of about $0.06 \mathrm{~nm} / \mathrm{K}$. The reflectance spectra were recorded from an as-grown sample, and the photoluminescence spectra were recorded from a sample with diamond heat spreader having an anti-reflective coating on it.

2.2. Operation at Fundamental Wavelength. The gain mirror wafer was cut into $2.5 \times 2.5 \mathrm{~mm}^{2}$ chips, which were then capillary-bonded to synthetic diamond heat spreaders with a wedge angle of about $2^{\circ}$ to alleviate the spectral modulation caused by the etalon effect. In addition, we applied a 2-layer $\mathrm{TiO}_{2} / \mathrm{SiO}_{2}$ antireflective coating on top of the diamond. The laser chip was clamped onto a copper heat sink having small water cooling channels. Despite the flow of cooling water within the heat sink, the heat load generated by pumping the gain mirror led to a slight increase in the mount temperature ( $\left.T_{\text {mount }}\right)$. The dependence of $T_{\text {mount }}$ on the pump power is shown in Figure 7 for three different pump spot diameters ( $\left.\phi_{\text {pump }}\right)$ and two different temperatures of the cooling water $\left(T_{\text {water }}\right)$. For laser characterization, the gain chips were tested in a V-shaped SDL cavity shown in Figure 8. The distance 


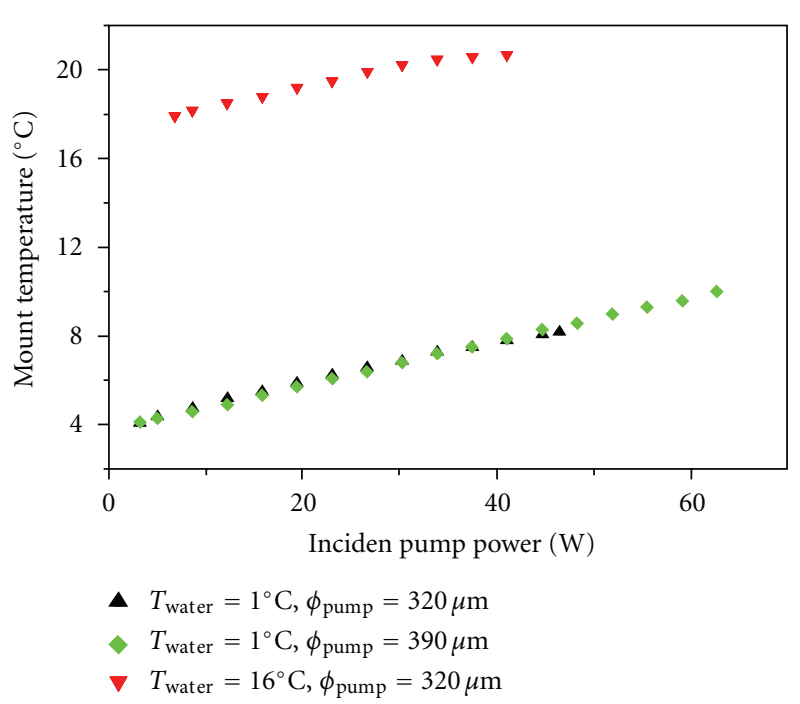

(a)

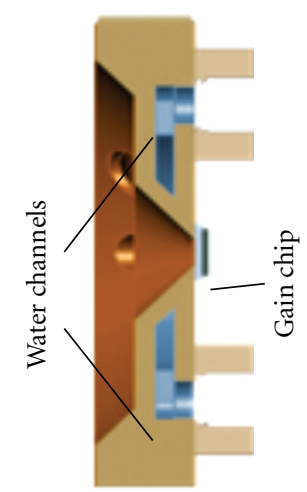

(b)

Figure 7: (a) The dependence of the mount temperature on the pump power for three diameters of the pump spot and two temperatures of the cooling water. (b) Drawing of the water-cooled mount.

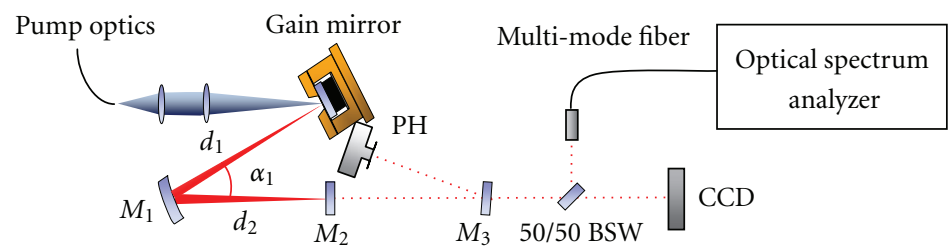
$M_{1}$ : High reflectivity mirror, radius of curvature $=75 \mathrm{~mm}$
$M_{2}$ : Output coupler with transmission, $T=0.1-3 \%$
$M_{3}$ : Partial reflector $T=0.7 \%$,

FIGURE 8: Description of the setup used for the spectrum and beam shape measurements.

between $M_{1}$ and $M_{2}$ was adjusted to match the size of the $\mathrm{TEM}_{00}$ mode to the pump spot on the gain chip, while monitoring the intensity of the output beam to resemble as close as possible a circular Gaussian geometry. In the experiments presented here the gain mirror was pumped by an $808 \mathrm{~nm}$ diode bar coupled to a $200 \mu \mathrm{m}$ multimode fiber. The incidence angle of the pump beam was about $27^{\circ}$.

The SDL output characteristics for different output couplers are shown in Figure 9. Here the water temperature was set to $16^{\circ} \mathrm{C}$ and the diameter of the pump spot to $320 \mu \mathrm{m}$. The maximum output power before thermal roll-over was achieved with $1.5 \%$ transmissive output coupler. The highest slope efficiency, of $27 \%$, corresponded to a coupling ratio of $3 \%$. The threshold pump power varied in the range of $3-7 \mathrm{~W}$ when the output coupling ratio was varied from 0.1 to $3 \%$.

Next, in order to optimize the pump spot for reaching highest possible power, $T_{\text {water }}$ was set to $1^{\circ} \mathrm{C}$. The results shown in Figure 10 reveal that the maximum output power increased when $\phi_{\text {pump }}$ was increased from $320 \mu \mathrm{m}$ to $390 \mu \mathrm{m}$.
Also the pump power at which the thermal roll-over was observed was increased from $45 \mathrm{~W}$ to $63 \mathrm{~W}$. An output power of slightly more than $11 \mathrm{~W}$ was reached with a pump spot of $\phi_{\text {pump }}=390 \mu \mathrm{m}$; the effective mount temperature was $10^{\circ} \mathrm{C}$. When $\phi_{\text {pump }}$ was increased from $390 \mu \mathrm{m}$ to $460 \mu \mathrm{m}$, the thermal roll-over point increased slightly to $70 \mathrm{~W}$. However, the slope efficiency dropped and the output power stayed below $11 \mathrm{~W}$, allegedly because of nonideal heat extraction from the gain mirror [99] or overlapping of the larger pump beam with defects on the gain mirror.

2.3. Frequency Doubling. To generate yellow-orange radiation via frequency doubling, we have used V-shape cavity as shown in Figure 11. The nonlinear conversion experiments were performed in free-running mode, that is, without any wavelength control. Compared to the cavity used for fundamental wavelength, the output coupler has been replaced by a mirror that was highly reflective for both IR and visible, whereas the folding mirror reflects infrared but transmits 


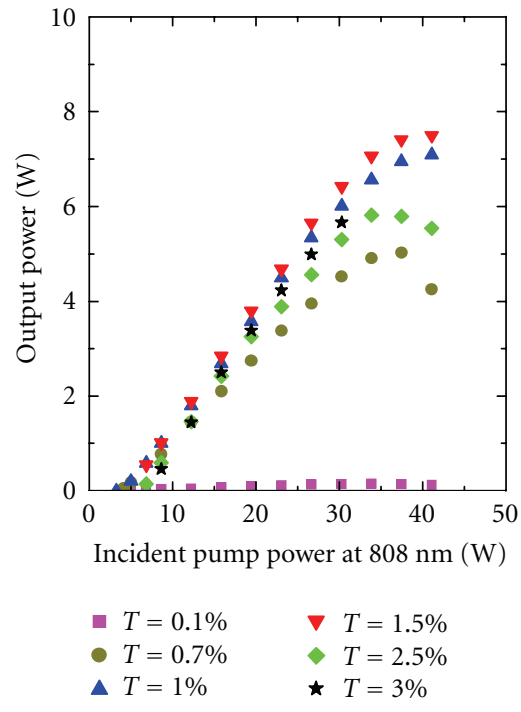

(a)

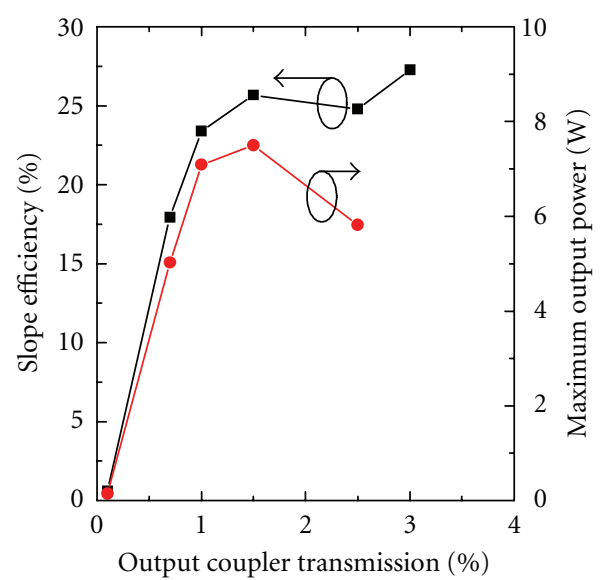

(b)

FIGURE 9: Output characteristics of the $1.18 \mu \mathrm{m}$ SDL for different output couplers. The temperature of the cooling water was set to $16^{\circ} \mathrm{C}$ and the diameter of the pump spot was $\sim 320 \mu \mathrm{m}[20]$.

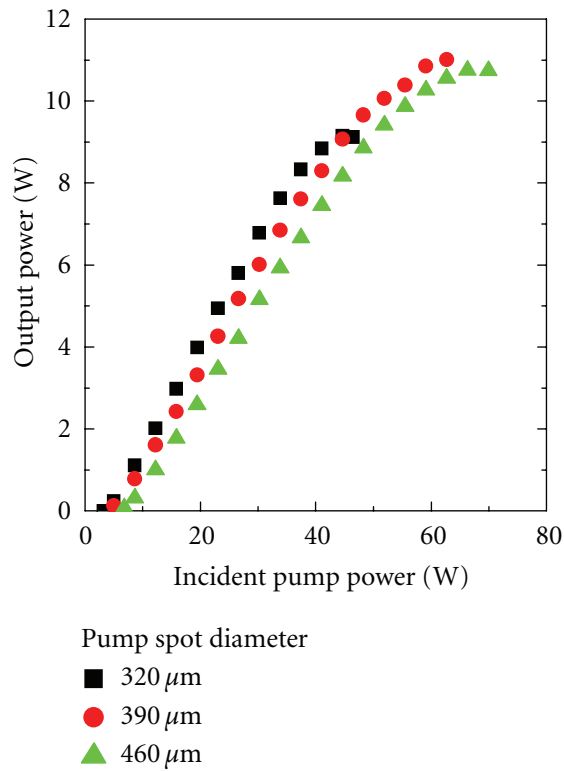

(a)

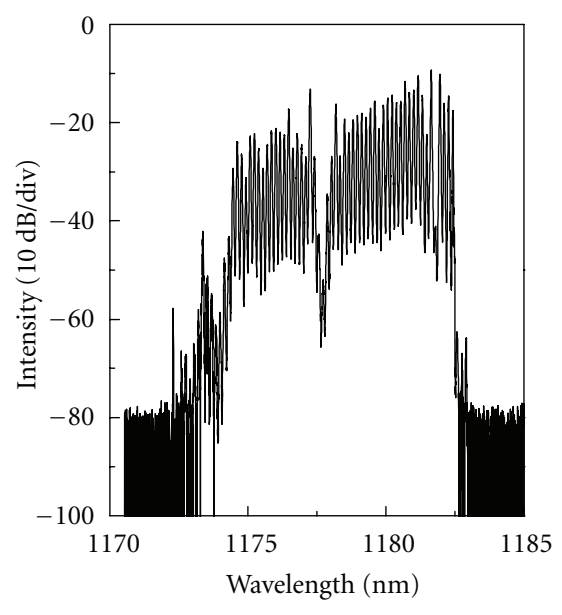

(b)

Figure 10: Output characteristic (a) and typical spectrum for an output power of $5 \mathrm{~W}$ (b). The temperature of the cooling water was set to $1{ }^{\circ} \mathrm{C}$ and the transmission of output coupler was $1.5 \%[20]$.

visible light. The frequency conversion was achieved using a $4 \mathrm{~mm}$ long type-I critically phase-matched BBO crystal. Figure 12 shows a power transfer graph comparison between the SDL emitting at fundamental infrared wavelength of $\sim 1180 \mathrm{~nm}$ and frequency-doubled light at $590 \mathrm{~nm}$. For a pump power of $41.5 \mathrm{~W}$, we demonstrated a maximum conversion efficiency (absorbed pump light to frequencyconverted light) of $17 \%$, which to our knowledge is the highest efficiency reported for a yellow SDL. The ratio of absorbed light to incident pump power was estimated to be $\sim 0.94$. At this pump power level, the output power of frequency-doubled light was about $77 \%$ of that obtained at 


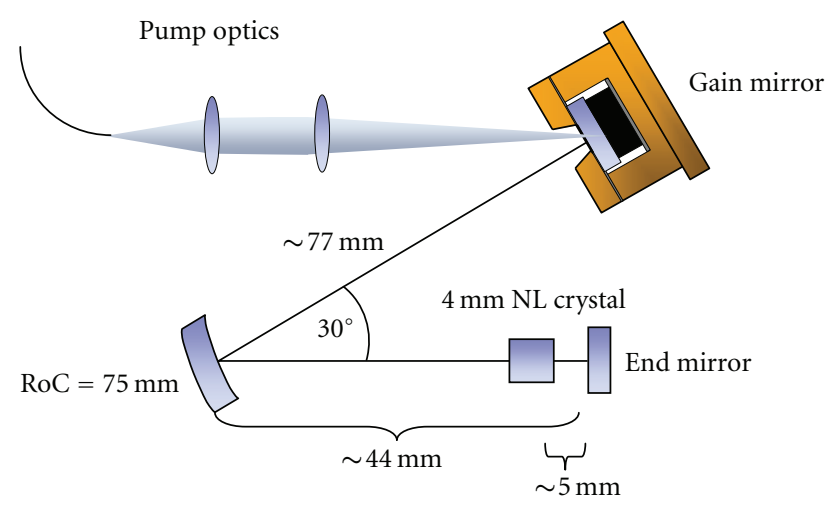

FIGURE 11: SDL setup used for yellow second-harmonic generation in free-running mode.

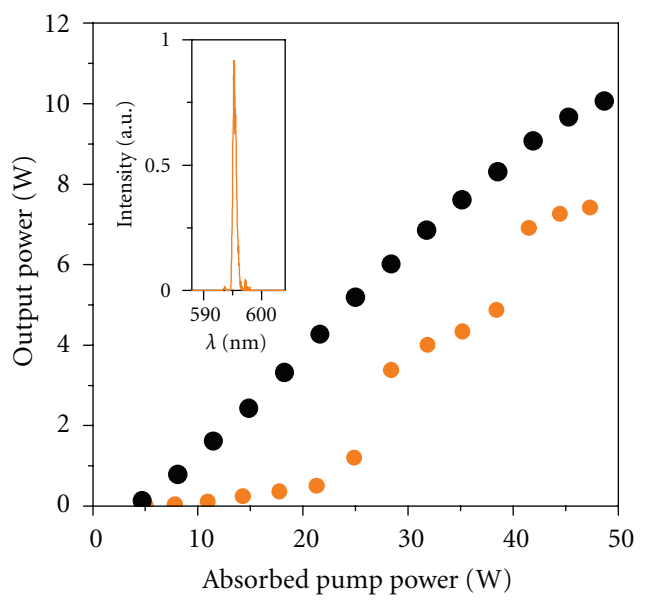

(a)

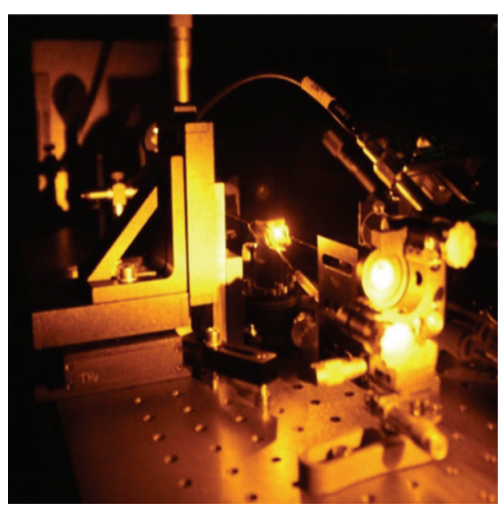

(b)

FIGURE 12: Power transfer graphs of an SDL emitting fundamental $1180 \mathrm{~nm}$ light (black) and of a frequency doubled SDL (orange). The inset shows the output spectrum of the frequency-doubled SDL. The photograph at right shows an SDL in operation.

the fundamental wavelength with similar lasing conditions. The inset of Figure 12 shows the emission spectrum of the frequency-doubled radiation at $7 \mathrm{~W}$ of output.

Based on the result discussed previously we can conclude that GaInNAs gain mirror technology is the leading candidates for realizing high-power SDLs with emission at yellow-orange wavelengths.

\section{GaSb-Based SDLs for $2-3 \mu \mathrm{m}$ Wavelength Range}

Another commercially and scientifically very interesting spectral domain is that located between 2 and $3 \mu \mathrm{m}$. This spectral range can be accessed using GaSb material system. GaSb-based SDLs with high-power $(>1 \mathrm{~W})$ and widely tunable (up to $\sim 160 \mathrm{~nm}$ ) operations have been reported by several groups $[19,37,65,100,101]$. In addition to continuous wave lasers also ultrashort pulse SDLs in this wavelength range are of interest, as they could be used as seed sources for mid-IR supercontinuum sources [102] or for pumping of mid-IR optical parametric oscillators. However, because of limited availability of some essential components, such as like semiconductor saturable absorber mirrors (SESAMs), the first passively mode-locked $2 \mu \mathrm{m}$ GaSb-based SDLs were reported only very recently $[103,104]$.

The development of GaSb-based (AlGaIn)(AsSb) heterostructures designed for $2-3 \mu \mathrm{m}$ wavelength range has struggled with many obstacles, such as increased Auger recombination, typical in narrow bandgap semiconductors, and reduced carrier confinement leading to type-II band alignment in QWs instead of preferred type-I. Regardless, electrically pumped, edge-emitting lasers based on GaSb epitaxy have demonstrated CW operation even beyond $3 \mu \mathrm{m}$ $[105,106]$ with careful band-gap engineering and utilization of quinternary AlGaInAsSb waveguides. For optical pumping, the decreased thermal properties of GaSb compared to conventional GaAs make thermal management more demanding for mid-IR SDLs. Typically, the optical pumping is based on commercially available diode pumps at 780$980 \mathrm{~nm}$ wavelength range, causing excessive heating due to a large quantum defect. The power scalability of GaSb-based SDLs is therefore limited by the effectiveness of thermal management [21]. To reduce the thermal load, different methods have been investigated, such as in-well pumping [19], a flip-chip process with GaSb substrate removal [26], and the use of high thermal conductivity substrate, such as Si or GaAs, in combination with metamorphic growth [107].

The benefits brought by GaSb-based material system to SDLs are the high index contrast $(\Delta \mathrm{n} \sim 0.6)$ of latticematched $\mathrm{AlAs}_{0.08} \mathrm{Sb}_{0.92} / \mathrm{GaSb}$ DBR layers, which enables to achieve high reflectivity in exceptionally broad band $(\sim 300 \mathrm{~nm}[100])$ with a relatively small number of layer pairs. This makes GaSb SDLs very attractive for spectroscopic application where broad tunability of the laser is needed. High-quality AlAsSb/GaSb DBR can also be used for SESAMs [108]. GaAs-based 1- $\mu \mathrm{m}$ SESAMs have been exploited extensively and their properties can be nowadays tailored to produce ultrashort pulses in various laser types. However, investigation of GaSb-based SESAMs has received far less attention [109, 110]. SESAMs operating at wavelengths around $2 \mu \mathrm{m}$ and above would have a significant impact on the development of practical ultrafast lasers required in medical applications and time-resolved 
molecular spectroscopy, or as seeders for optical amplifiers and mid-IR supercontinuum lasers.

To our knowledge the first diode-pumped GaSb-based SDL was demonstrated by Cerutti et al. [111] in 2004; the $2.3 \mu \mathrm{m}$ laser reached lasing at temperatures up to $350 \mathrm{~K}$ with quite moderate output powers. Currently, the emission wavelengths of GaSb SDLs cover the 1.96-2.8 $\mu \mathrm{m}$ spectral range $[66,100]$. At $2-2.35 \mu \mathrm{m}$ the $\mathrm{CW}$ power levels have reached multiple watts $[37,112]$ for near room temperature operation. The achieved output powers of $0.6 \mathrm{~W}$ at $2.5 \mu \mathrm{m}$ and $0.1 \mathrm{~W}$ at $2.8 \mu \mathrm{m}[66,72]$ have not yet reclaimed the position as such SDLs as high-power lasers. Here, our work had two primary targets: (1) obtain as high CW power as possible at $2 \mu \mathrm{m}$ and (2) produce ultrashort pulses by passive mode locking at $2 \mu \mathrm{m}$. We have developed a gain mirror structure grown on GaSb substrate by solid source MBE. The design included an 18.5-pair DBR made of lattice matched $\mathrm{AlAsSb} / \mathrm{GaSb}$ layers, and a gain region with $15 \mathrm{InGaSb}$ QWs. For continuous wave experiments, the SDL mirrors were bonded to a planar intracavity diamond heat spreader in a similar manner as the GaInNAs samples described previously. Details of the fabrication process are provided in [37].

3.1. Continuous Wave GaSb Disk Laser. Our $2 \mu \mathrm{m}$ range SDLs employed a V-shaped laser cavity. The output characteristics obtained with $99-97 \%$ reflective couplers are shown in Figure 13. Here the cooling water temperature was set to $3.5^{\circ} \mathrm{C}$ and the pump spot diameter was about $350 \mu \mathrm{m}$. The emission wavelength was about $1990 \mathrm{~nm}$ (Figure 13), slightly depending on the power and output coupler. We observed a general tendency for a spectrum shift towards longer wavelengths with increased coupler reflectance, which could be caused by different heat loads on the gain.

The output characteristics were also measured as a function of the cooling water temperature (Figure 14) using a $98 \%$ reflective coupler. The available maximum power was reduced with increasing temperature but it is worth noting that for a coolant temperature of $45^{\circ} \mathrm{C}$ the laser still produced nearly $1 \mathrm{~W}$ of output power. In order to further increase the output power, the pump spot diameter was increased from $350 \mu \mathrm{m}$ to $440 \mu \mathrm{m}$ which enabled a maximum power of $5.75 \mathrm{~W}$ to be achieved at a water temperature of $3.5^{\circ} \mathrm{C}$.

While the power from a single gain chip was limited to less than $6 \mathrm{~W}$, we studied also the possibility to increase the laser output by cascading 2 gain chips in one laser cavity. A $\mathrm{W}$-shaped laser cavity was set up as shown in Figure 15. The pump spot diameter was further increased to $500 \mu \mathrm{m}$ and the temperature was reduced to $-2.5^{\circ} \mathrm{C}$. For this purpose a mixture of water and alcohol had to be used as coolant and a flow of nitrogen was provided to the samples to prevent condensation of water from the surrounding air. Eventually we were able to increase the power to $8.6 \mathrm{~W}$ (Figure 15) but could not achieve linear power scaling that should have theoretically resulted in more than $11 \mathrm{~W}$ of power with these two particular chips. Reasons for this can be many. One important contributing factor may be the output coupler that was $94.6 \%$ reflective; out of all available output couplers it enabled the highest output power but might not have been

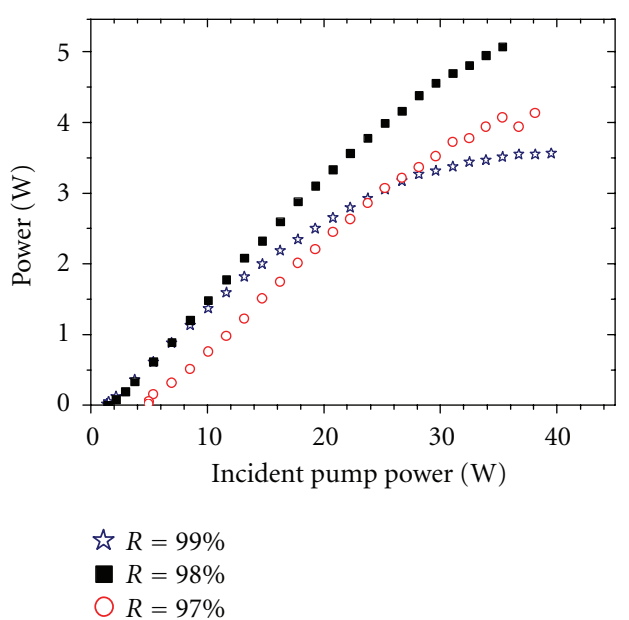

(a)

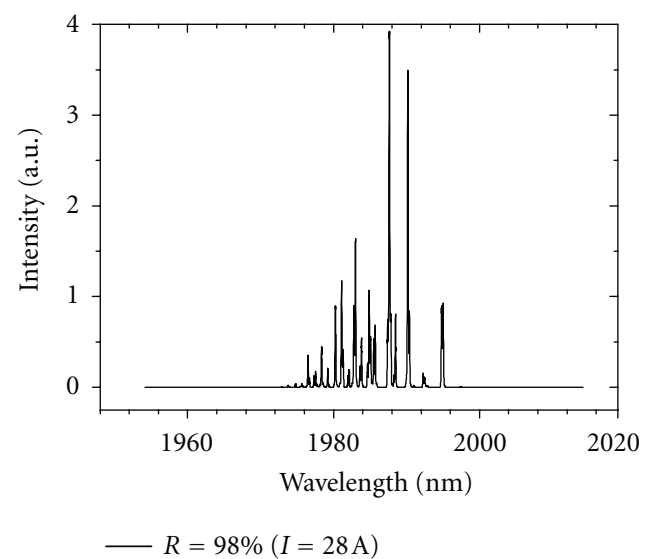

(b)

FIGURE 13: (a) Laser output for different output couplers. $T=3.5^{\circ} \mathrm{C}$ (cooling water temperature). Pump spot $\varnothing=350 \mu \mathrm{m}$. R : output coupler reflectivity. (b) Laser spectrum for a pump power of $35.2 \mathrm{~W}$.

optimal for this particular laser configuration. The coolant mixture had also lower specific heat than pure water and therefore the cooling may not be as effective as the coolant temperature could suggest. The 2-gain laser alignment is also somewhat more complicated than a single chip laser which may hinder power scaling. Despite these difficulties, reasonable results were obtained in terms of output power at $2 \mu \mathrm{m}$ wavelength.

3.2. Femtosecond Pulse Generation. As discussed earlier, ultrashort optical pulses have been generated in GaAs- and InP-based disk lasers in various configurations using both active and passive mode-locking schemes $[2,4,6,44,45,113$, 114]. On the contrast, the development of ultrafast $\mathrm{GaSb}$ disk lasers has been much slower, possibly due to lack of SESAMs and more demanding SESAM characterization. We have shown only very recently that also GaSb-based disk laser can generate sub-picoseconds pulses at $2 \mu \mathrm{m}$ [104]. The development of low-nonlinearity GaSb-based SESAMs was 


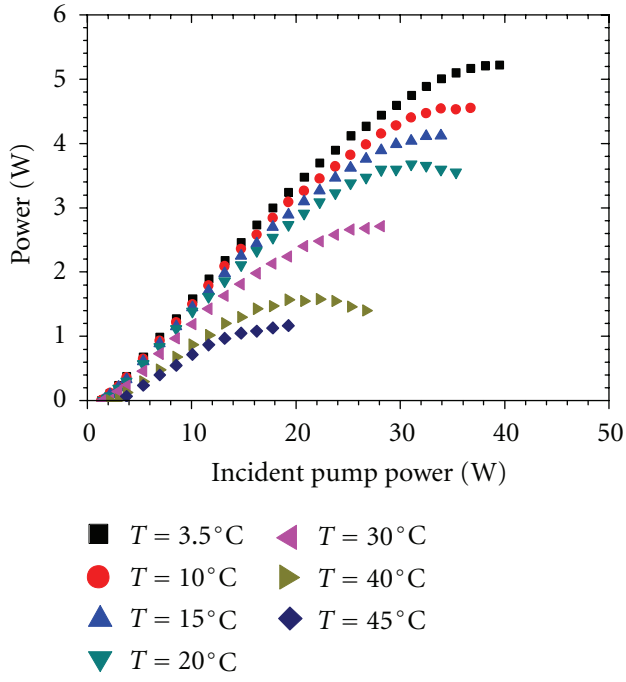

(a)

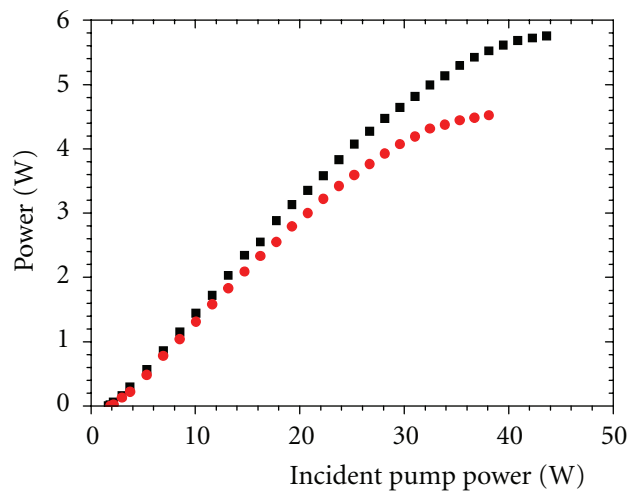

$3.5^{\circ} \mathrm{C}$

$15^{\circ} \mathrm{C}$

(b)

FIGURE 14: (a) Laser output characteristics at different cooling water temperatures. Output coupler $\mathrm{R}$ is $98 \%$, and pump spot diameter is $350 \mu \mathrm{m}$. (b) Laser output characteristics with $440 \mu \mathrm{m}$ pump spot diameter. Output coupler $R$ is $98 \%$.

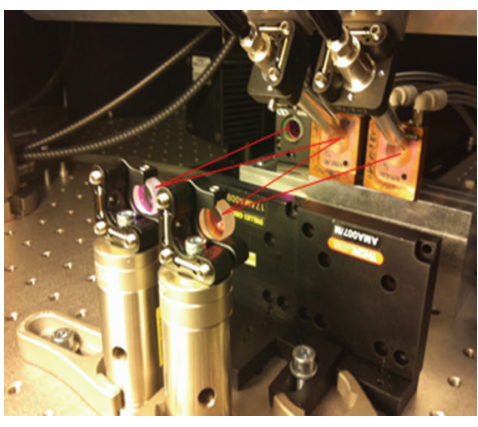

(a)

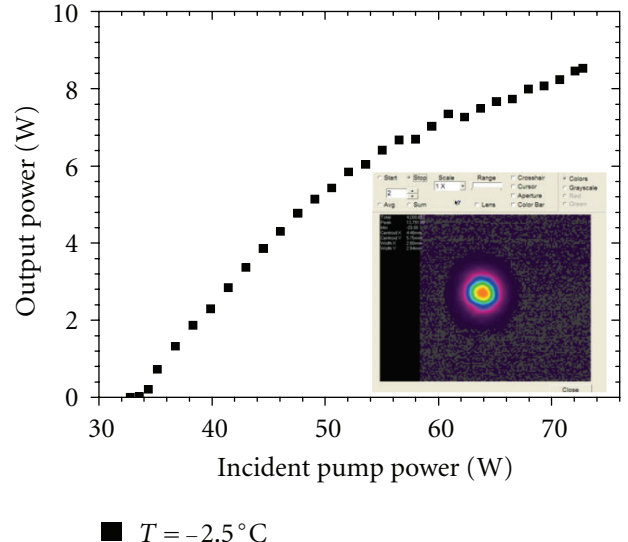

(b)

Figure 15: (a) Photograph of the W-shaped 2-gain laser cavity. (b) 2-gain laser output characteristics with $500 \mu \mathrm{m}$ pump spot diameter. Output coupler $R$ is $94.6 \%$. Inset: profile of the output beam.

instrumental for demonstrating ultrafast $2 \mu \mathrm{m}$ SDLs. The right combination of the dynamic properties of the SESAM (saturation fluence, absorption recovery time, nonlinear reflectivity, and nonsaturable losses) is quite essential for achieving stable mode-locking. An interesting finding was made that as-grown $2 \mu \mathrm{m} \mathrm{GaSb}$ saturable absorber mirrors had much faster recovery time than typical as-grown GaAsbased components operating in the $1 \mu \mathrm{m}$ regime. Fabrication details of the SESAMs we have used are provided in reference [110]. The GaSb absorber mirrors were studied with pump probe measurements. The growth temperature and amount of strain were used as controlled variables. For the modelocking experiments, we used a Z-shaped cavity (Figure 16) that allowed convenient alignment of the SESAM and gain mirror.

The gain chip was cooled in a similar manner as the continuous wave $2 \mu \mathrm{m}$ laser, but the heat spreader diamond had a $2^{\circ}$ wedge and AR coating to suppress the etalon effect arising from it. The gain mirror was pumped with a fiber-coupled $980 \mathrm{~nm}$ diode laser and the output coupler had a reflectivity of $R=99 \%$ at the operation wavelength. Simulated mode diameter was $\sim 230 \mu \mathrm{m}$ on the gain and $\sim 25 \mu \mathrm{m}$ on the SESAM. The pulse repetition rate, defined by the cavity length, was in the order of $890 \mathrm{MHz}$. The output of the laser was monitored with an optical spectrum analyzer and a $2.5 \mathrm{GHz}$ photodiode from which the signal 


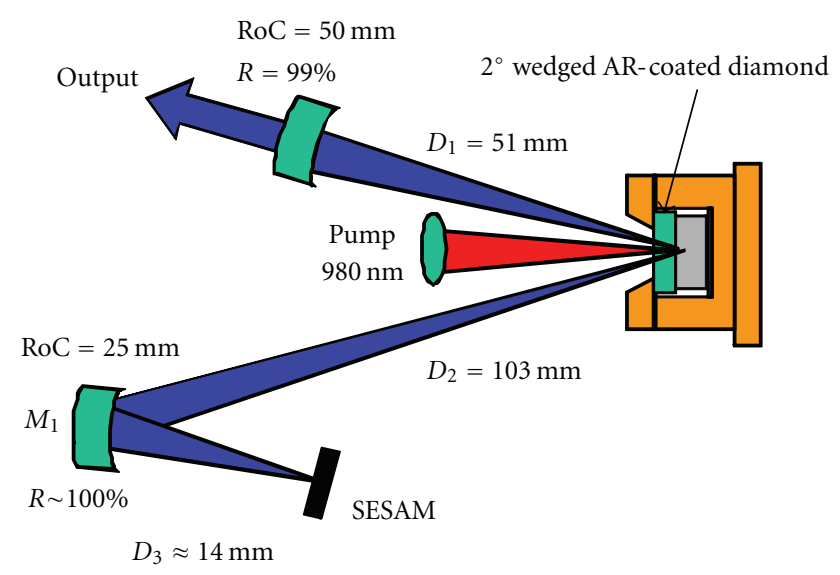

FIGURE 16: A Z-shaped cavity of the mode-locked GaSb laser.

was coupled to an RF-analyzer and oscilloscope. The laser beam profile could be monitored with a pyroelectric camera for proper alignment. The pulses were characterized with an interferometric autocorrelator that was based on two-photon absorption in a silicon detector. Depending on the laser alignment, we were able to measure pulses with duration varying from slightly less than $400 \mathrm{fs}$ to slightly more than $400 \mathrm{fs}$, with the shortest measured pulse being $384 \mathrm{fs}$. A typical autocorrelation trace is shown in Figure 17 with the optical spectrum, RF-spectrum, and retrieved pulse shape.

Quite surprisingly the output power level of the modelocked laser was only some tens of milliwatts despite many watts of pump power. In continuous wave mode over $5 \mathrm{~W}$ of power was obtained from other devices having similar gain material. To some extent the differences can be explained by variations between individual chips, nonoptimal output coupling ratio, lossy cavity, and smaller pump spot diameter but clearly the average power in mode-locked operation should have been markedly higher. In order to study the potential of the laser, we replaced the SESAM with a high reflective mirror and then we measured the output power in continuous wave mode. As shown in Figure 18, for an incident pump power of $7.6 \mathrm{~W}$, the power was $\sim 23 \mathrm{~mW}$ with the SESAM, and slightly over $40 \mathrm{~mW}$ with the HR mirror.

The precise position of the mirror could be determined from the RF-spectrum, which helped to monitor the output power as a function of the mirror position in regard to the original position of the SESAM. When the HR mirror was repositioned about $60 \mu \mathrm{m}$ closer to the curved mirror than the original SESAM position, the power increased from $40 \mathrm{~mW}$ to $130 \mathrm{~mW}$ (see Figure 19 for details). The position of the HR/absorber mirror changes the mode diameter also on the gain and therefore it has an impact on the efficiency of the laser. The study revealed that the mirror position that was optimal for mode-locking may not have been optimal for achieving the highest average power. The result suggests that with further optimization of the cavity geometry and adjustments of the pump spot diameter and output coupling ratio, it should be possible to increase the average power to $>100 \mathrm{~mW}$ also in mode-locked operation.

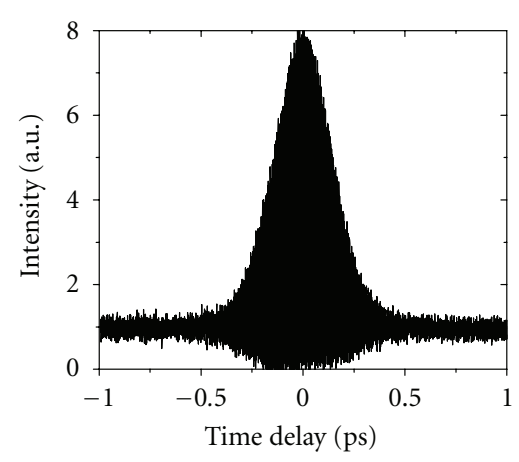

(a)

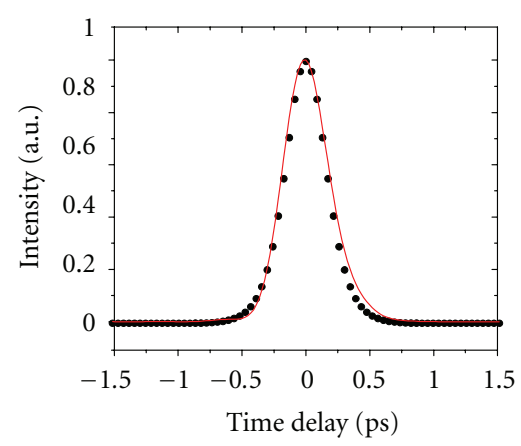

- Fourier limit Measured pulse

(b)



(c)

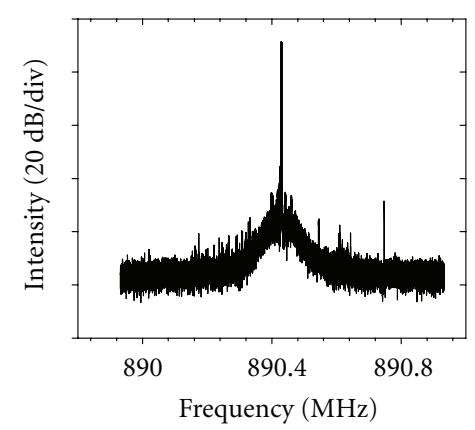

(d)

FIGURE 17: (a) Interferometric autocorrelation trace. (b) Intensity autocorrelation retrieved from the interferometric data. shown together with calculated Fourier limit. (c) Optical spectrum and a fitting. (d) Measured RF-spectrum. 


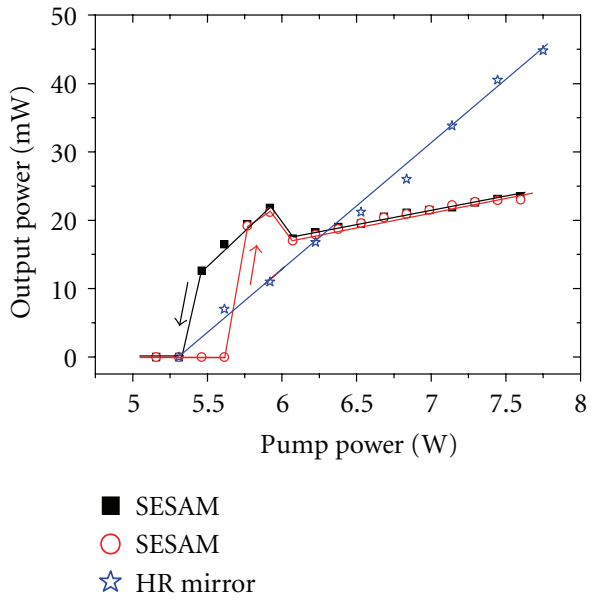

Figure 18: Average power of the GaSb SDL with a SESAM, and with a high reflective mirror. With the SESAM we can observe a hysteresis characteristic, typical for mode-locking.

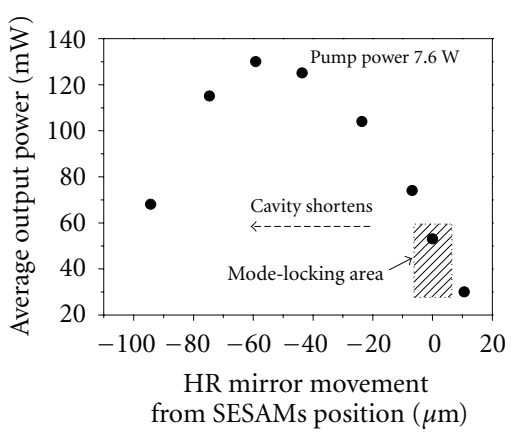

FIgure 19: Output power of the GaSb disk laser with the high reflective mirror, given as a function of the HR mirror's position in regard to the original SESAM's position (point of optimal modelocking).

To summarize, we have shown that nearly transform limited femtosecond pulses can be obtained from SESAM modelocked GaSb disk lasers without use of additional dispersion compensating elements. So far the power levels are modest but there is reason to believe that the average power could be increased beyond $100 \mathrm{~mW}$ with further optimization of the laser.

\section{Future Outlook}

SDLs (or VECSELs, or OPSLs) combine a small footprint, multiwatt output power capability, high beam quality, and the capability to fill spectral gaps that cannot be reached by traditional solid state disk lasers. In terms of semiconductor technology, OP-SDLs are in many aspects simpler than VCSELs; they do not require doping of the mirrors, usually make use of only one semiconductor mirror, and their processing is simpler. Owing to these advantageous features and intense developments efforts in the last decade, SDLs have reached a development stage that makes them very attractive for application deployments. While SDLs with emission at green or blue have been commercialized for several years by Coherent Inc., there are other wavelength regions where SDLs could have a tremendous impact on the development of new applications. Leveraging the advantages of SDLs technology to broader wavelength domains is inherently linked to the development of new semiconductor structures enabling wavelength tailoring and increased functionality.

In this paper, we reviewed the main advances in the development of SDLs producing yellow-orange and $2 \mu \mathrm{m}$ radiation, which are required in medicine, astronomy, life science research, sensing, or infrared countermeasures. GaInNAs/GaAs gain mirrors are now a reliable approach for the development of SDLs with fundamental emission of more than $11 \mathrm{~W}$ at around $1180-1200 \mathrm{~nm}$. This material system has enabled generation of yellow-orange laser radiation with excellent beam quality and output power exceeding $7 \mathrm{~W}$ (the highest power obtained from a semiconductor-based laser at this wavelength range). The GaSb gain mirrors have been used to leverage the advantages offered by SDLs to the 2$3 \mu \mathrm{m}$ wavelength range. This material system is very robust in terms of reliability and life-time, enabling one to reach output powers in excess of several watts at wavelengths of 2$2.3 \mu \mathrm{m}$. Most recently, we have demonstrated that GaSb SDLs are suitable for generation of femtosecond pulses at $2-\mu \mathrm{m}$, a wavelength range that is particularly attractive for surgery, infrared counter measures, or LIDAR, and where there is a lack of compact high-power ultrashort pulse sources. Despite these achievements, there are certainly several development steps that are required for reaching new functionality and for advancing the technology to levels suitable for application deployment. The main development directions we undertake for the advances of dilute-nitride and GaSb-based SDLs are briefly discussed as follows.

Development of flip-chip technology for dilute nitride SDLs, would enable further improvements of the spectral and power characteristics. The main limitation of using intracavity heat spreader is related to spectral modulation caused by spurious etalon effects, which have a detrimental effect on wavelength tuning and mode-locking. Allegedly, the flip-chip technology would also enable a more predictable power scaling with increasing the area of the pump region on the gain mirror. The main difficulty related to the use of flip-chip technology for dilute-nitrides is apparently related to the high level of residual strain corresponding to the GaInNAs active region; the strain leads to occurrence of structural defects due to mechanical deformation once the substrate is removed. Advanced strain compensation techniques are expected to alleviate this problem.

Flip-chip technology could provide advantages to GaSbbased SDLs for increased functionality and development of a process that is more suitable for volume production. In particular, we should note that wavelength-tuning capability is very important for mid-IR SDLs as many of the applications could be related to spectroscopy. The main difficulty related to the use of flip-chip technology for GaSb is related to the fact that this material system is less developed from processing point of view. Successful steps in GaSb SDL flip-chip processing and development of adequate etch stop layers for substrate removal have been already made [26]. Very recently 
we have also demonstrated that InPSb can be used effectively as an etch stop layer for the GaSb substrate removal; we have achieved an etch selectivity of GaSb substrate as high as 244 and excellent substrate removal rate of $32.4 \mu \mathrm{m} / \mathrm{min}$ [115]. The flip-chip GaSb gain mirrors would be beneficial for ultrashort pulse operation and could ultimately enable to take full advantage of the broad gain bandwidth of GaSb.

Development of electrically pumped GaSb SDLs. While optically pumped SDLs can produce multiple watts of output power, they require a separate pump source that adds to the cost and complexity of the device. Direct electrical-pumping offers an interesting alternative that simplifies the overall laser scheme. If the power level is not the main target, electrically pumping of SDLs, more often termed as EP-VECSELs, can be realized conveniently [116]. The essential challenges of electrical pumping relate to nonuniform current spreading and optical losses in doped semiconductor material [117-119]. Doping is necessary for achieving low electrical resistance, but at the same time it does increase absorption. On the other hand, the current spreading problems limit the size of usable gain area and therefore hinder power scaling. Despite several technical challenges, EP-VECSELs have been studied actively and there have been also serious attempts to commercialize this type of laser [120,121]. Using standard GaAs gain mirrors output power levels in excess of $400 \mathrm{~mW}$ have been reported [122]. On the contrary GaSb-based EP-VECSELs have been demonstrated only recently [123]. For this preliminary demonstration, we have used a (1/2)VCSEL gain mirror $(\lambda \sim 2.3 \mu \mathrm{m})$ that was fabricated at the Walter Schottky Institute in Germany. An I-shaped cavity was formed between the gain mirror and a curved output coupler. In a first study we tested 7 different components with diameters of 30-90 $\mu \mathrm{m}$. Lasing was obtained from all components at $15^{\circ} \mathrm{C}$ mount temperature using pulsed current with $1 \mu$ s pulse width and $3 \%$ duty cycle. A maximum peak power of $1.5 \mathrm{~mW}$ was obtained from the $60 \mu \mathrm{m}$ component. Thermal issues seemed to be the major factor limiting the power. We should note here that electrical pumping is particularly attractive for mid-IR GaSb VECSELs, as the requirements for deployment in spectroscopic applications are mainly related to compactness, tunability, single-frequency lasers, and less to the power level. An EP-VECSEL would be compact but at the same time would enable to include intracavity elements for wavelength tuning in a broad wavelength range or would enable the use of intracavity spectroscopy in compact and efficient laser architectures.

\section{Acknowledgments}

The authors would like to thank several colleagues and external collaborators for continuous contribution to the development of SDLs reviewed here. In particular, Janne Puustinen, Jonna Paajaste, and Riku Koskinen are acknowledged for MBE fabrication of the semiconductor structures, and Lasse Orsila and Jari Nikkinen are acknowledged for their help with the deposition of antireflection coatings. They thank Jukka-Pekka Alanko, Christian Grebing, and Professor Günter Steinmeyer for their contribution to the demonstration of $2-\mu \mathrm{m}$ mode-locked SDL. They acknowledge Professor Anne Tropper from the University of Southampton for useful discussion and sharing some of the data presented in Figure 3. They thank Professor Amann and his group from the Walter Schottky Institute for fabricating the $2.3 \mu \mathrm{m}$ EP-VECSEL samples they reported in [123]. They gratefully acknowledge the financial support provided by by Areté Associates, Pirkanmaa TE-center, the Finnish Funding Agency for Development and Innovation (TEKES), the Academy of Finland (no. 128364), the Graduate Schools in Material Science and GETA, and the United States Office of Naval Research Global (ONRG) under the Grant no. N62909-10-1-7030.

\section{References}

[1] N. Basov, O. Bogdankevich, and A. Grasyuk, "9B4-semiconductor lasers with radiating mirrors," Quantum Electronics, vol. 2, no. 9, pp. 594-597, 1966.

[2] W. B. Jiang, S. R. Friberg, H. Iwamura, and Y. Yamamoto, "High powers and subpicosecond pulses from an externalcavity surface-emitting InGaAs/InP multiple quantum well laser," Applied Physics Letters, vol. 58, no. 8, pp. 807-809, 1991.

[3] H. Q. Le, S. Di Cecca, and A. Mooradian, "Scalable highpower optically pumped GaAs laser," Applied Physics Letters, vol. 58, no. 18, pp. 1967-1969, 1991.

[4] W. H. Xiang, S. R. Friberg, K. Watanabe et al., "Sub-100 femtosecond pulses from an external-cavity surface-emitting InGaAs/InP multiple quantum well laser with soliton-effect compression," Applied Physics Letters, vol. 59, no. 17, pp. 2076-2078, 1991.

[5] D. C. Sun, S. R. Friberg, K. Watanabe, S. MacHida, Y. Horikoshi, and Y. Yamamoto, "High power and high efficiency vertical cavity surface emitting GaAs laser," Applied Physics Letters, vol. 61, no. 13, pp. 1502-1503, 1992.

[6] W. B. Jiang, R. Mirin, and J. E. Bowers, "Mode-locked GaAs vertical cavity surface emitting lasers," Applied Physics Letters, vol. 60, no. 6, pp. 677-679, 1992.

[7] C. Symonds, J. Dion, I. Sagnes et al., "High performance $1.55 \mu \mathrm{m}$ vertical external cavity surface emitting laser with broadband integrated dielectric-metal mirror," Electronics Letters, vol. 40, no. 12, pp. 734-735, 2004.

[8] D. Lorenser, H. J. Unold, D. J. H. C. Maas et al., “Towards wafer-scale integration of high repetition rate passively mode-locked surface-emitting semiconductor lasers," $A p$ plied Physics B, vol. 79, no. 8, pp. 927-932, 2004.

[9] M. Kuznetsov, F. Hakimi, R. Sprague, and A. Mooradian, "Design and characteristics of high-power $(>0.5$ W CW) diode-pumped vertical-external-cavity surfaceemitting semiconductor lasers with circular TEM 00 beams," IEEE Journal on Selected Topics in Quantum Electronics, vol. 5, no. 3, pp. 561-573, 1999.

[10] E. J. Saarinen, A. Härkönen, S. Suomalainen, and O. G. Okhotnikov, "Power scalable semiconductor disk laser using multiple gain cavity," in Proceedings of the Conference on Lasers and Electro-Optics (CLEO '07), 2007.

[11] L. Fan, M. Fallahi, J. Hader et al., "Multichip vertical-external-cavity surface-emitting lasers: a coherent power scaling scheme," Optics Letters, vol. 31, no. 24, pp. 3612-3614, 2006. 
[12] T. J. Ochalski, A. De Burea, G. Huyet et al., "Passively modelocked bi-directional vertical external ring cavity surface emitting laser," in Proceedings of the Conference on Quantum Electronics and Laser Science Conference on Lasers and ElectroOptics (CLEO/QELS '08), May 2008.

[13] J. E. Hastie, J. M. Hopkins, C. W. Jeon et al., "Microchip vertical external cavity surface emitting lasers," Electronics Letters, vol. 39, no. 18, pp. 1324-1326, 2003.

[14] S. A. Smith, J. M. Hopkins, J. E. Hastie et al., "Diamondmicrochip GaInNAs vertical external-cavity surface-emitting laser operating CW at $1315 \mathrm{~nm}$," Electronics Letters, vol. 40, no. 15, pp. 935-936, 2004.

[15] N. Laurand, C. L. Lee, E. Gu, J. E. Hastie, S. Calvez, and M. D. Dawson, "Microlensed microchip VECSEL," Optics Express, vol. 15, no. 15, pp. 9341-9346, 2007.

[16] S. W. Corzine, R. S. Geels, J. W. Scott, R. H. Yan, and L. A. Coldren, "Design of Fabry-Perot surface-emitting lasers with a periodic gain structure," IEEE Journal of Quantum Electronics, vol. 25, no. 6, pp. 1513-1524, 1989.

[17] M. Schmid, S. Benchabane, F. Torabi-Goudarzi, R. Abram, A. I. Ferguson, and E. Riis, "Optical in-well pumping of a vertical-external-cavity surface-emitting laser," Applied Letters, vol. 84, no. 24, pp. 4860-4862, 2004.

[18] S. S. Beyertt, U. Brauch, F. Demaria et al., "Efficient galliumarsenide disk laser," IEEE Journal of Quantum Electronics, vol. 43, no. 10, pp. 869-875, 2007.

[19] N. Schulz, M. Rattunde, C. Ritzenthaler et al., "Resonant optical in-well pumping of an (AlGaIn)(AsSb)-based vertical-external-cavity surface-emitting laser emitting at $2.35 \mu \mathrm{m}$," Applied Physics Letters, vol. 91, no. 9, Article ID 091113, 2007.

[20] V. M. Korpijärvi, T. Leinonen, J. Puustinen, A. Härkönen, and M. D. Guina, " $11 \mathrm{~W}$ single gain-chip dilute nitride disk laser emitting around $1180 \mathrm{~nm}$," Optics Express, vol. 18, no. 25, pp. 25633-25641, 2010.

[21] A. J. Kemp, G. J. Valentine, J. M. Hopkins et al., "Thermal management in vertical-external-cavity surface-emitting lasers: finite-element analysis of a heatspreader approach," IEEE Journal of Quantum Electronics, vol. 41, no. 2, pp. 148155, 2005.

[22] W. J. Alford, T. D. Raymond, and A. A. Allerman, "High power and good beam quality at $980 \mathrm{~nm}$ from a vertical external-cavity surface-emitting laser," Journal of the Optical Society of America B, vol. 19, no. 4, pp. 663-666, 2002.

[23] J. E. Hastie, J. M. Hopkins, S. Calvez et al., "0.5-W single transverse-mode operation of an $850 \mathrm{~nm}$ diode-pumped surface-emitting semiconductor laser," IEEE Photonics Technology Letters, vol. 15, no. 7, pp. 894-896, 2003.

[24] Z. L. Liau, "Semiconductor wafer bonding via liquid capillarity," Applied Physics Letters, vol. 77, no. 5, pp. 651-653, 2000.

[25] M. Kuznetsov, F. Hakimi, R. Sprague, and A. Mooradian, "High-power $(>0.5-\mathrm{W}$ CW) diode-pumped verticalexternal-cavity surface-emitting semiconductor lasers with circular TEM 00 beams," IEEE Photonics Technology Letters, vol. 9, no. 8, pp. 1063-1065, 1997.

[26] J. P. Perez, A. Laurain, L. Cerutti, I. Sagnes, and A. Garnache, "Technologies for thermal management of mid-IR Sbbased surface emitting lasers," Semiconductor Science and Technology, vol. 25, no. 4, Article ID 045021, 2010.

[27] A. R. Clawson, "Guide to references on III-V semiconductor chemical etching," Materials Science and Engineering $R$, vol. 31, no. 1, pp. 1-438, 2001.

[28] A. J. Maclean, A. J. Kemp, S. Calvez et al., "Continuous tuning and efficient intracavity second-harmonic generation in a semiconductor disk laser with an intracavity diamond heatspreader," IEEE Journal of Quantum Electronics, vol. 44, no. 3, pp. 216-225, 2008.

[29] T. L. Wang, Y. Kaneda, J. M. Yarborough et al., "High-power optically pumped semiconductor laser at $1040 \mathrm{~nm}$," IEEE Photonics Technology Letters, vol. 22, no. 9, Article ID 5422654, pp. 661-663, 2010.

[30] J. Chilla, Q. Shu, H. Zhou, E. Weiss, M. Reed, and L. Spinelli, "Recent advances in optically pumped semiconductor lasers," in Solid State Lasers XVI: Technology and Devices, vol. 6451 of Proceedings of SPIE, San Jose, Calif, USA, 2007.

[31] H. Lindberg, M. Strassner, E. Gerster, J. Bengtsson, and A. Larsson, "Thermal management of optically pumped longwavelength InP-based semiconductor disk lasers," IEEE Journal on Selected Topics in Quantum Electronics, vol. 11, no. 5, pp. 1126-1134, 2005.

[32] A. J. Kemp, A. J. MacLean, J. E. Hastie et al., "Thermal lensing, thermal management and transverse mode control in microchip VECSELs," Applied Physics B, vol. 83, no. 2, pp. 189-194, 2006.

[33] A. J. Maclean, R. B. Birch, P. W. Roth, A. J. Kemp, and D. Burns, "Limits on efficiency and power scaling in semiconductor disk lasers with diamond heatspreaders," Journal of the Optical Society of America B, vol. 26, no. 12, pp. 2228-2236, 2009.

[34] A. R. Zakharian, J. Hader, J. V. Moloney, S. W. Koch, P. Brick, and S. Lutgen, "Experimental and theoretical analysis of optically pumped semiconductor disk lasers," Applied Physics Letters, vol. 83, no. 7, pp. 1313-1315, 2003.

[35] L. Fan, M. Fallahi, J. T. Murray et al., "Tunable high-power high-brightness linearly polarized vertical-external-cavity surface-emitting lasers," Applied Physics Letters, vol. 88, no. 2, Article ID 021105, pp. 1-3, 2006.

[36] L. Fan, M. Fallahi, A. R. Zakharian et al., "Extended tunability in a two-chip VECSEL," IEEE Photonics Technology Letters, vol. 19, no. 8, pp. 544-546, 2007.

[37] J. Paajaste, S. Suomalainen, R. Koskinen, A. Härkönen, M. Guina, and M. Pessa, "High-power and broadly tunable GaSb-based optically pumped VECSELs emitting near $2 \mu \mathrm{m}$," Journal of Crystal Growth, vol. 311, no. 7, pp. 1917-1919, 2009.

[38] C. Borgentun, J. Bengtsson, A. Larsson, F. Demaria, A. Hein, and P. Unger, "Optimization of a broadband gain element for a widely tunable high-power semiconductor disk laser," IEEE Photonics Technology Letters, vol. 22, no. 13, Article ID 5451056, pp. 978-980, 2010.

[39] M. A. Holm, D. Burns, A. I. Ferguson, and M. D. Dawson, "Actively stabilized single-frequency vertical-external-cavity AlGaAs laser," IEEE Photonics Technology Letters, vol. 11, no. 12, pp. 1551-1553, 1999.

[40] H. Lindberg, A. Larsson, and M. Strassner, "Single-frequency operation of a high-power, long-wavelength semiconductor disk laser," Optics Letters, vol. 30, no. 17, pp. 2260-2262, 2005.

[41] A. Laurain, M. Myara, G. Beaudoin, I. Sagnes, and A. Garnache, "Multiwatt-power highly-coherent compact singlefrequency tunable vertical-external-cavity-surface-emittingsemiconductor-laser," Optics Express, vol. 18, no. 14, pp. 14627-14636, 2010.

[42] B. Rudin, A. Rutz, M. Hoffmann et al., "Highly efficient optically pumped vertical-emitting semiconductor laser with more than $20 \mathrm{~W}$ average output power in a fundamental transverse mode," Optics Letters, vol. 33, no. 22, pp. 27192721, 2008.

[43] J. Chilla, S. Butterworth, A. Zeitschel et al., "High power optically pumped semiconductor lasers," in Solid State Lasers 
XIII: Technology and Devices, vol. 5332 of Proceedings of SPIE, pp. 143-150, San Jose, Calif, USA, 2004.

[44] A. H. Quarterman, K. G. Wilcox, V. Apostolopoulos et al., "A passively mode-locked external-cavity semiconductor laser emitting 60 fs pulses," Nature Photonics, vol. 3, no. 12, pp. 729-731, 2009.

[45] P. Klopp, F. Saas, M. Zorn, M. Weyers, and U. Griebner, " $290 \mathrm{fs}$ pulses from a semiconductor disk laser," Optics Express, vol. 16, no. 8, pp. 5770-5775, 2008.

[46] A. Aschwanden, D. Lorenser, H. J. Unold, R. Paschotta, E. Gini, and U. Keller, " $2.1 \mathrm{~W}$ picosecond passively modelocked external-cavity semiconductor laser," Optics Letters, vol. 30, no. 3, pp. 272-274, 2005.

[47] B. Rudin, V. J. Wittwer, D. J. H. C. Maas et al., "High-power MIXSEL: an integrated ultrafast semiconductor laser with $6.4 \mathrm{~W}$ average power," Optics Express, vol. 18, no. 26, pp. 27582-27588, 2010.

[48] D. Lorenser, D. J. H. C. Maas, H. J. Unold et al., “50 GHz passively mode-locked surface-emitting semiconductor laser with $100 \mathrm{~mW}$ average output power," IEEE Journal of Quantum Electronics, vol. 42, no. 8, Article ID 01658136, pp. 838$847,2006$.

[49] U. Keller and A. C. Tropper, "Passively modelocked surfaceemitting semiconductor lasers," Physics Reports, vol. 429, no. 2, pp. 67-120, 2006.

[50] W. Zhang, A. McDonald, T. Ackemann, E. Riis, and G. McConnell, "Femtosecond synchronously in-well pumped vertical-external-cavity surface-emitting laser," Optics Express, vol. 18, no. 1, pp. 187-192, 2010.

[51] J. Rautiainen, V. M. Korpijärvi, J. Puustinen, M. Guina, and O. G. Okhotnikov, "Passively mode-locked GaInNAs disk laser operating at $1220 \mathrm{~nm}$," Optics Express, vol. 16, no. 20, pp. 15964-15969, 2008.

[52] A. Rutz, V. Liverini, D. J. H. C. Maas et al., "Passively modelocked GaInNAs VECSEL at centre wavelength around $1.3 \mu \mathrm{m}$," Electronics Letters, vol. 42, no. 16, pp. 926-927, 2006.

[53] A. Khadour, S. Bouchoule, G. Aubin, J. C. Harmand, J. Decobert, and J. L. Oudar, "Ultrashort pulse generation from $1.56 \mu \mathrm{m}$ modelocked VECSEL at room temperature," Optics Express, vol. 18, no. 19, pp. 19902-19913, 2010.

[54] J. E. Hastie, L. G. Morton, A. J. Kemp, M. D. Dawson, A. B. Krysa, and J. S. Roberts, "Tunable ultraviolet output from an intracavity frequency-doubled red vertical-external-cavity surface-emitting laser," Applied Physics Letters, vol. 89, no. 6, Article ID 061114, 2006.

[55] S. H. Park, J. Kim, H. Jeon et al., "Room-temperature GaN vertical-cavity surface-emitting laser operation in an extended cavity scheme," Applied Physics Letters, vol. 83, no. 11, pp. 2121-2123, 2003.

[56] J. Y. Kim, S. Cho, S. J. Lim et al., "Efficient blue lasers based on gain structure optimizing of vertical-external-cavity surfaceemitting laser with second harmonic generation," Journal of Applied Physics, vol. 101, no. 3, Article ID 033103, 2007.

[57] J. Lee, S. Lee, T. Kim, and Y. Park, "7 W high-efficiency continuous-wave green light generation by intracavity frequency doubling of an end-pumped vertical external-cavity surface emitting semiconductor laser," Applied Physics Letters, vol. 89, no. 24, Article ID 241107, 2006.

[58] S. Hilbich, W. Seelert, V. Ostroumov et al., "New wavelengths in the yellow orange range between $545 \mathrm{~nm}$ to $580 \mathrm{~nm}$ generated by an intracavity frequency-doubled Optically Pumped Semiconductor Laser," in Solid State Lasers XVI: Technology and Devices, vol. 6451 of Proceedings of SPIE, San Jose, Calif, USA, 2007.
[59] A. Härkönen, J. Rautiainen, M. Guina et al., "High power frequency doubled GaInNAs semiconductor disk laser emitting at 615 nm," Optics Express, vol. 15, no. 6, pp. 3224-3229, 2007.

[60] M. I. Müller, N. Linder, C. Karnutsch et al., "Optically pumped semiconductor thin-disk laser with external cavity operating at $660 \mathrm{~nm}$," in Vertical-Cavity Surface-Emitting Lasers VI, vol. 4649 of Proceedings of SPIE, pp. 265-271, San Jose, Calif, USA, 2002.

[61] K. S. Kim, J. R. Yoo, S. H. Cho et al., "1060 nm vertical-external-cavity surface-emitting lasers with an optical-tooptical efficiency of $44 \%$ at room temperature," Applied Physics Letters, vol. 88, no. 9, Article ID 091107, 2006.

[62] J. Konttinen, A. Härkönen, P. Tuomisto et al., "High-power $(>1 \mathrm{~W})$ dilute nitride semiconductor disk laser emitting at 1240 nm," New Journal of Physics, vol. 9, article 140, 2007.

[63] J. M. Hopkins, S. A. Smith, C. W. Jeon et al., "0.6 W CW GaInNAs vertical external-cavity surface emitting laser operating at $1.32 \mu \mathrm{m}$," Electronics Letters, vol. 40, no. 1, pp. 30-31, 2004.

[64] H. Lindberg, M. Strassner, E. Gerster, and A. Larsson, “ $0.8 \mathrm{~W}$ optically pumped vertical external cavity surface emitting laser operating CW at $1550 \mathrm{~nm}$," Electronics Letters, vol. 40, no. 10, pp. 601-602, 2004.

[65] J. Nikkinen, J. Paajaste, R. Koskinen, S. Suomalainen, and O. G. Okhotnikov, "GaSb-based semiconductor disk laser with $130 \mathrm{~nm}$ tuning range at $2.5 \mu \mathrm{m}$," IEEE Photonics Technology Letters, vol. 23, no. 12, Article ID 5723696, pp. 777-779, 2011.

[66] B. Rösener, M. Rattunde, R. Moser et al., "Continuous-wave room-temperature operation of a $2.8 \mu \mathrm{m} \mathrm{GaSb}$-based semiconductor disk laser," Optics Letters, vol. 36, no. 3, pp. 319321, 2011.

[67] M. Rahim, A. Khiar, F. Felder, M. Fill, and H. Zogg, “ $4.5 \mu \mathrm{m}$ wavelength vertical external cavity surface emitting laser operating above room temperature," Applied Physics Letters, vol. 94, no. 20, Article ID 201112, 2009.

[68] M. Rahim, F. Felder, M. Fill, and H. Zogg, "Optically pumped $5 \mu \mathrm{m}$ IV-VI VECSEL with Al-heat spreader," Optics Letters, vol. 33, no. 24, pp. 3010-3012, 2008.

[69] Y. Kaneda, J. M. Yarborough, L. Li et al., "Continuous-wave all-solid-state $244 \mathrm{~nm}$ deep-ultraviolet laser source by fourthharmonic generation of an optically pumped semiconductor laser using $\mathrm{CsLiB}_{6} \mathrm{O}_{10}$ inanexternalresonator," Optics Letters, vol. 33, no. 15, pp. 1705-1707, 2008.

[70] T. Leinonen, J. Puustinen, V. -M. Korpijärvi, A. Härkönen, M. Guina, and R. J. Epstein, "Generation of high power $(>7 \mathrm{~W})$ yellow-orange radiation by frequency doubling of GaInNAs-based semiconductor disk laser," in Proceedings of the Conference on Lasers and Electro-Optics Europe and 12th European Quantum Electronics Conference (CLEO EUROPE/ EQEC'11), 2011.

[71] J. Rautiainen, A. Härkönen, V.-M. Korpijärvi et al., "Red and UV generation using frequency-converted GaInNAs-based semiconductor disk laser," in Proceedings of the Conference on Lasers and Electro-Optics and 2009 Conference on Quantum Electronics and Laser Science Conference (CLEO/QELS '09), 2009.

[72] J. Paajaste, R. Koskinen, J. Nikkinen, S. Suomalainen, and O. G. Okhotnikov, "Power scalable $2.5 \mu \mathrm{m}$ (AlGaIn)(AsSb) semiconductor disk laser grown by molecular beam epitaxy," Journal of Crystal Growth, vol. 323, pp. 454-456, 2010.

[73] J. M. Hopkins, N. Hempler, B. Rösener et al., "5 W Mid-IR optically-pumped semiconductor disk laser," in Proceedings of the Conference on Quantum Electronics and Laser Science 
Conference on Lasers and Electro-Optics (CLEO/QELS '08), May 2008.

[74] A. Rantamäki, A. Sirbu, A. Mereuta, E. Kapon, and O. G. Okhotnikov, " $3 \mathrm{~W}$ of $650 \mathrm{~nm}$ red emission by frequency doubling of wafer-fused semiconductor disk laser," Optics Express, vol. 18, no. 21, pp. 21645-21650, 2010.

[75] J. Lyytikäinen, J. Rautiainen, A. Sirbu et al., "High-power $1.48 \mu \mathrm{m}$ wafer-fused optically pumped semiconductor disk laser," vol. 23, no. 13, pp. 917-919, 2011.

[76] J. Rautiainen, J. Lyytikäinen, A. Sirbu et al., "2.6 W opticallypumped semiconductor disk laser operating at $1.57-\mu \mathrm{m}$ using wafer fusion," Optics Express, vol. 16, no. 26, pp. 2188121886, 2008.

[77] B. Lambert, Y. Toudic, Y. Rouillard et al., "High reflectivity $1.55 \mu \mathrm{m}$ (Al)GaAsSb/AlAsSb Bragg reflector lattice matched on InP substrates," Applied Physics Letters, vol. 66, pp. 442444, 1995.

[78] I. F. L. Dias, B. Nabet, A. Kohl, J. L. Benchimol, and J. C. Harmand, "Electrical and optical characteristics of n-typedoped distributed bragg mirrors on InP," IEEE Photonics Technology Letters, vol. 10, no. 6, pp. 763-765, 1998.

[79] Y. Imajo, A. Kasukawa, S. Kashiwa, and H. Okamoto, "GaInAsP/InP semiconductor multilayer reflector grwon by metalorganic chemical vapor deposition and its application to surface emitting laser diode," Japanese Journal of Applied Physics, vol. 29, no. 7, pp. 1130-1132, 1990.

[80] J. H. Baek, I. H. Choi, B. Lee, W. S. Han, and H. K. Cho, "Precise control of $1.55 \mu \mathrm{m}$ vertical-cavity surface-emitting laser structure with InAlGaAs/InAlAs Bragg reflectors by in situ growth monitoring," Applied Physics Letters, vol. 75, no. 11, pp. 1500-1502, 1999.

[81] E. Gerster, I. Ecker, S. Lorch, C. Hahn, S. Menzel, and P. Unger, "Orange-emitting frequency-doubled GaAsSb/GaAs semiconductor disk laser," Journal of Applied Physics, vol. 94, no. 12, pp. 7397-7401, 2003.

[82] J. Lyytikäinen, J. Rautiainen, L. Toikkanen et al., "1.3- $\mu \mathrm{m}$ optically-pumped semiconductor disk laser by wafer fusion," Optics Express, vol. 17, no. 11, pp. 9047-9052, 2009.

[83] T. D. Germann, A. Strittmatter, U. W. Pohl et al., "Quantumdot semiconductor disk lasers," Journal of Crystal Growth, vol. 310, no. 23, pp. 5182-5186, 2008.

[84] J. Rautiainen, I. Krestnikov, M. Butkus, E. U. Rafailov, and O. G. Okhotnikov, "Optically pumped semiconductor quantum dot disk laser operating at $1180 \mathrm{~nm}$," Optics Letters, vol. 35, no. 5, pp. 694-696, 2010.

[85] L. Fan, C. Hessenius, M. Fallahi et al., "Highly strained InGaAsGaAs multiwatt vertical-external-cavity surfaceemitting laser emitting around $1170 \mathrm{~nm}$," Applied Physics Letters, vol. 91, no. 13, Article ID 131114, 2007.

[86] K. J. Beernink, P. K. York, J. J. Coleman, R. G. Waters, J. Kim, and C. M. Wayman, "Characterization of InGaAs-GaAs strained-layer lasers with quantum wells near the critical thickness," Applied Physics Letters, vol. 55, no. 21, pp. 21672169, 1989.

[87] G. Jaschke, R. Averbeck, L. Geelhaar, and H. Riechert, "Low threshold InGaAsN/GaAs lasers beyond $1500 \mathrm{~nm}$," Journal of Crystal Growth, vol. 278, no. 1-4, pp. 224-228, 2005.

[88] W. Walukiewicz, W. Shan, J. Wu, K. M. Yu, and J. W. Ager, "Band anticrossing and related electronic structure in III-NV alloys," in Dilute Nitride Semiconductors, M. Henin, Ed., pp. 325-359, Elsevier, 2005.

[89] E. P. O’Reilly, A. Lindsay, S. Fahy, S. Tomic, and P. J. Klar, “A tight-binding based analysis of the band anti-crossing model and its application in $\mathrm{Ga}(\mathrm{In}) \mathrm{NAs}$ alloys," in Dilute Nitride Semiconductors, M. Henini, Ed., pp. 361-391, Elsevier, 2005.

[90] W. Walukiewicz, K. Alberi, J. Wu, W. Shan, K. M. Yu, and J. W. Ager, Electronic Band Structure of Highly Mismatched Semiconductor Alloys, Springer, 2008.

[91] I. Vurgaftman and J. R. Meyer, "Band parameters for nitrogen-containing semiconductors," Journal of Applied Physics, vol. 94, no. 6, pp. 3675-3696, 2003.

[92] D. J. Palmer, P. M. Smowton, P. Blood, J. Y. Yeh, L. J. Mawst, and N. Tansu, "Effect of nitrogen on gain and efficiency in InGaAsN quantum-well lasers," Applied Physics Letters, vol. 86, no. 7, Article ID 071121, pp. 1-3, 2005.

[93] W. M. McGee, R. S. Williams, M. J. Ashwin et al., "Structure, morphology, and optical properties of $\mathrm{Ga}_{x} \mathrm{In}_{1-x} \mathrm{~N}_{0.05} \mathrm{As}_{0.95}$ quantum wells: influence of the growth mechanism," Physical Review B, vol. 76, no. 8, Article ID 085309, 2007.

[94] J. Miguel-Sánchez, A. Guzmán, J. M. Ulloa, A. Hierro, and E. Muñoz, "Effect of nitrogen ions on the properties of InGaAsN quantum wells grown by plasma-assisted molecular beam epitaxy," IEE Proceedings: Optoelectronics, vol. 151, no. 5, pp. 305-308, 2004.

[95] A. Y. Egorov, D. Bernklau, D. Livshits, V. Ustinov, Z. I. Alferov, and H. Riechert, "High power CW operation of InGaAsN lasers at $1.3 \mu \mathrm{m}$," Electronics Letters, vol. 35, no. 19, pp. 1643-1644, 1999.

[96] O. Ambacher, "Growth and applications of group III-nitrides," Journal of Physics D, vol. 31, no. 20, pp. 2653-2710, 1998.

[97] H. Carrère, A. Arnoult, A. Ricard, and E. Bedel-Pereira, "RF plasma investigations for plasma-assisted MBE growth of (Ga,In)(As,N) materials," Journal of Crystal Growth, vol. 243, no. 2, pp. 295-301, 2002.

[98] E. M. Pavelescu, T. Hakkarainen, V. D. S. Dhaka et al., "Influence of arsenic pressure on photoluminescence and structural properties of GaInNAs/GaAs quantum wells grown by molecular beam epitaxy," Journal of Crystal Growth, vol. 281, no. 2-4, pp. 249-254, 2005.

[99] S. Giet, A. J. Kemp, D. Burns et al., "Comparison of thermal management techniques for semiconductor disk lasers," in Solid State Lasers XVII: Technology and Devices, vol. 6871 of Proceedings of SPIE, San Jose, Calif, USA, 2008.

[100] A. Härkönen, M. Guina, O. Okhotnikov et al., "1-W antimonide-based vertical external cavity surface emitting laser operating at 2- $\mu \mathrm{m}$," Optics Express, vol. 14, no. 14, pp. 64796484, 2006.

[101] J. M. Hopkins, N. Hempler, B. Rösener et al., "High-power, (AlGaIn)(AsSb) semiconductor disk laser at $2.0 \mu \mathrm{m}$," Optics Letters, vol. 33, no. 2, pp. 201-203, 2008.

[102] J. H. V. Price, T. M. Monro, H. Ebendorff-Heidepriem et al., "Mid-IR supercontinuum generation from nonsilica microstruetured optical fibers," IEEE Journal on Selected Topics in Quantum Electronics, vol. 13, no. 3, pp. 738-749, 2007.

[103] A. Härkönen, J. Paajaste, S. Suomalainen et al., "Picosecond passively mode-locked GaSb-based semiconductor disk laser operating at $2 \mu \mathrm{m}$," Optics Letters, vol. 35, no. 24, pp. 40904092, 2010.

[104] A. Härkönen, C. Grebing, J. Paajaste et al., "Modelocked GaSb disk laser producing $384 \mathrm{fs}$ pulses at $2 \mathrm{~m}$ wavelength," Electronics Letters, vol. 47, no. 7, pp. 454-456, 2011.

[105] L. Shterengas, G. Belenky, T. Hosoda, G. Kipshidze, and S. Suchalkin, "Continuous wave operation of diode lasers at $3.36 \mu \mathrm{m}$ at $12^{\circ} \mathrm{C}$," Applied Physics Letters, vol. 93, no. 1, Article ID $011103,2008$. 
[106] T. Hosoda, G. Kipshidze, L. Shterengas, and G. Belenky, "Diode lasers emitting near $3.44 \mu \mathrm{m}$ in continuous-wave regime at $300 \mathrm{~K}$," Electronics Letters, vol. 46, no. 21, pp. 1455-1457, 2010.

[107] Y. Y. Lai, J. M. Yarborough, Y. Kaneda et al., "340-W peak power from a GaSb $2-\mu \mathrm{m}$ optically pumped semiconductor laser (OPSL) grown mismatched on GaAs," IEEE Photonics Technology Letters, vol. 22, no. 16, Article ID 5512584, pp. 1253-1255, 2010.

[108] U. Keller, K. J. Weingarten, F. X. Kärtner et al., "Semiconductor saturable absorber mirrors (SESAM's) for femtosecond to nanosecond pulse generation in solid-state lasers," IEEE Journal on Selected Topics in Quantum Electronics, vol. 2, no. 3, pp. 435-453, 1996.

[109] R. Koskinen, S. Suomalainen, J. Paajaste et al., "Highly nonlinear GaSb-based saturable absorber mirrors," in Nonlinear Optics and Applications III, vol. 7354 of Proceedings of SPIE, 2009.

[110] J. Paajaste, S. Suomalainen, R. Koskinen, A. Härkönen, G. Steinmeyer, and M. Guina, "GaSb-based semiconductor saturable absorber mirrors for mode-locking $2 \mu \mathrm{m}$ semiconductor disk lasers," Physica Status Solidi (C), Special Issue: 38th International Symposium on Compound Semiconductors (ISCS 2011), , vol. 9, no. 2, pp. 294-297, 2012.

[111] L. Cerutti, A. Garnache, A. Ouvrard, and F. Genty, "High temperature continuous wave operation of Sb-based vertical external cavity surface emitting laser near $2.3 \mu \mathrm{m}$," Journal of Crystal Growth, vol. 268, no. 1-2, pp. 128-134, 2004.

[112] M. Rattunde, N. Schulz, C. Ritzenthaler et al., "High brightness GaSb-based optically pumped semiconductor disk lasers at $2.3 \mu \mathrm{m}$," in Quantum Sensing and Nanophotonic Devices IV, vol. 6479 of Proceedings of SPIE, 2007.

[113] A. Garnache, S. Hoogland, A. C. Tropper, I. Sagnes, G. SaintGirons, and J. S. Roberts, "Sub-500-fs soliton-like pulse in a passively mode-locked broadband surface-emitting laser with $100 \mathrm{~mW}$ average power," Applied Physics Letters, vol. 80, no. 21, pp. 3892-3894, 2002.

[114] H. Lindberg, M. Sadeghi, M. Westlund et al., "Mode locking a $1550 \mathrm{~nm}$ semiconductor disk laser by using a GaInNAs saturable absorber," Optics Letters, vol. 30, no. 20, pp. 2793 2795, 2005.

[115] J. Lindfors, J. Paajaste, R. Koskinen, A. Härkönen, S. Suomalainen, and M. Guina, "Highly selective etch stop layer for GaSb substrate removal," in Proceedings of the 16th Semiconducting and Insulating Materials Conference (SIMCXVI'11), 2011.

[116] N. Yokouchi, T. Miyamoto, T. Uchida, Y. Inaba, F. Koyama, and K. Iga, "40 angstrom continuous tuning of a GaInAsP/ InP vertical-cavity surface-emitting laser using an external mirror," IEEE Photonics Technology Letters, vol. 4, no. 7, pp. 701-703, 1992.

[117] P. Kreuter, B. Witzigmann, D. J. H. C. Maas, Y. Barbarin, T. Südmeyer, and U. Keller, "On the design of electrically pumped vertical-external-cavity surface-emitting lasers," Applied Physics B, vol. 91, no. 2, pp. 257-264, 2008.

[118] J. R. Orchard, D. T.D. Childs, L. C. Lin, B. J. Stevens, D. M. Williams, and R. A. Hogg, "Design rules and characterisation of electrically pumped vertical external cavity surface emitting lasers," Japanese Journal of Applied Physics, vol. 50, no. 4, Article ID 04DG05, 2011.

[119] W. Schwarz, "Cavity optimization of electrically pumped VECSELs," II Annual Report, Institute of Optoelectronics, Ulm University, 2006.
[120] M. Jansen, B. D. Cantos, G. P. Carey et al., "Visible laser and laser array sources for projection displays," in Liquid Crystal Materials, Devices, and Applications XI, vol. 6135 of Proceedings of SPIE, 2006.

[121] A. Mooradian, S. Antikichev, B. Cantos et al., "High power extended vertical cavity surface emitting diode lasers and arrays and their applications," in Proceedings of the MicroOptics Conference, pp. 1-4, 2005.

[122] J. G. McInerney, A. Mooradian, A. Lewis et al., "High-power surface emitting semiconductor laser with extended vertical compound cavity," Electronics Letters, vol. 39, no. 6, pp. 523525, 2003.

[123] A. Härkönen, A. Bachmann, S. Arafin et al., " $2.34 \mu \mathrm{m}$ electrically-pumped VECSEL with buried tunnel junction," in Semiconductor Lasers and Laser Dynamics IV, vol. 7720 of Proceedings of SPIE, 2010. 

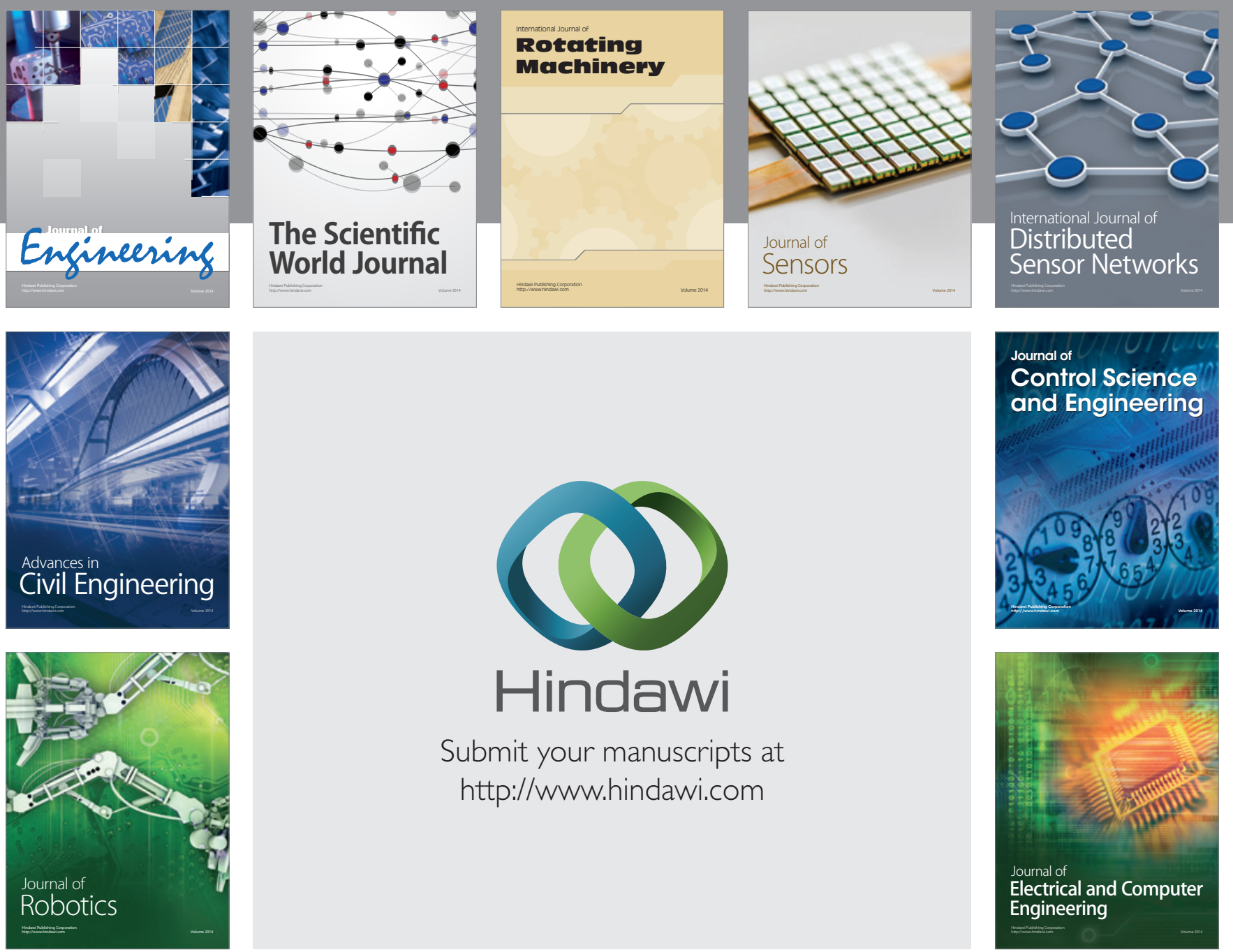

Submit your manuscripts at

http://www.hindawi.com
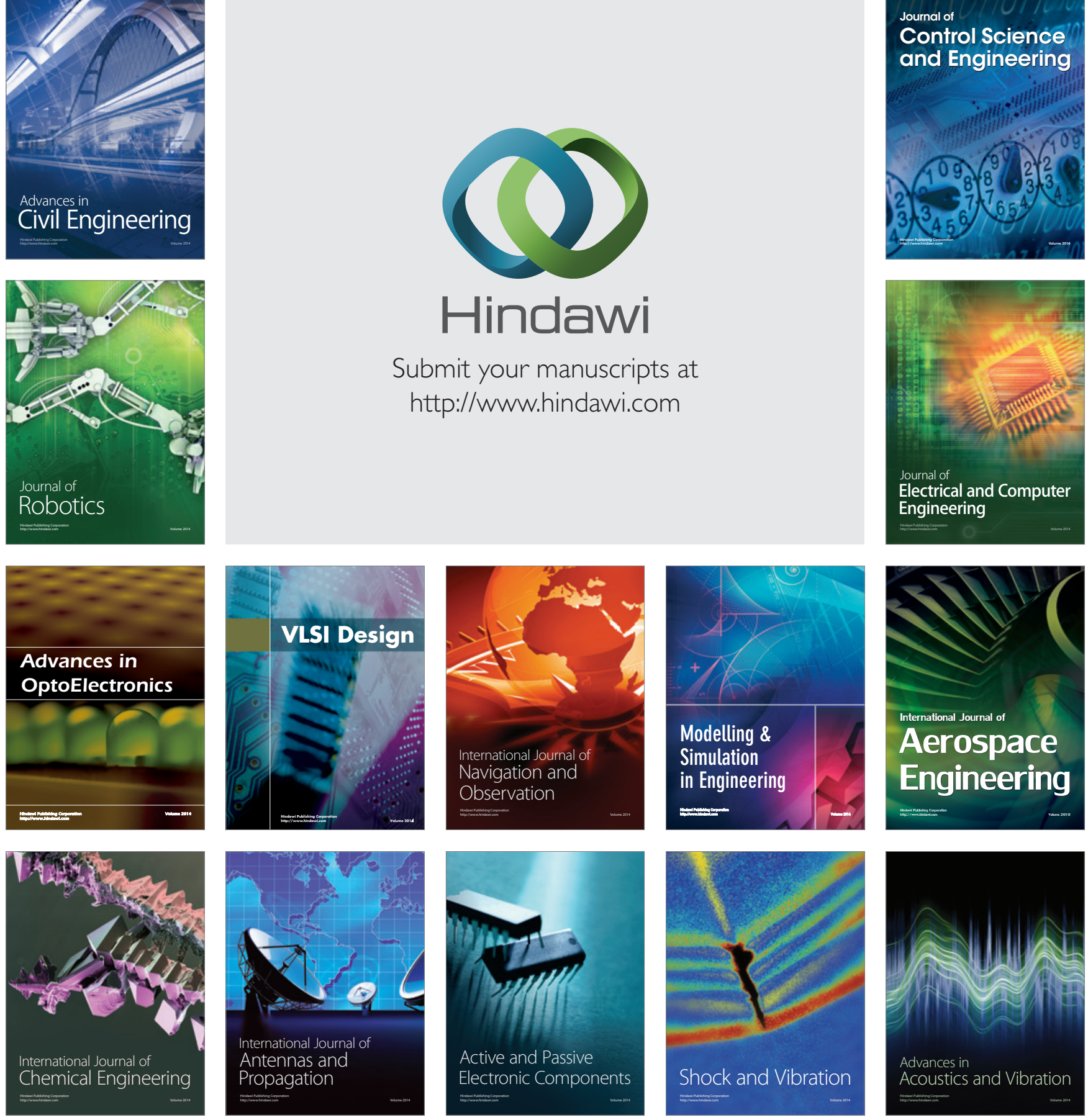